\title{
Cellular Analogs of Visual Cortical Epigenesis. I. Plasticity of Orientation Selectivity
}

\author{
Yves Frégnac, Daniel Shulz, Simon Thorpe, ${ }^{a}$ and Elie Bienenstock ${ }^{b}$ \\ Laboratoire de Neurobiologie et Neuropharmacologie du Développement, Université Paris XI, F.91405 Orsay Cedex, \\ France
}

\begin{abstract}
A differential pairing procedure was applied in vivo to individual neurons in the primary visual cortex of anesthetized paralyzed cats, in order to produce changes in their relative orientation preference. While we recorded from a single cell, its visual response to a light bar was driven iontophoretically to a "high" level when stimulating with an initially nonpreferred orientation $\left(\mathrm{S}^{+}\right)$, and alternately reduced to a "low" level when stimulating with the preferred orientation (S). This associative procedure was devised to test the possible role of neuronal coactivity in controlling the plasticity of orientation selectivity.
\end{abstract}

Among 87 cells tested, 35 (40\%) showed significant longlasting changes, either in the relative orientation preference for the two "paired" stimuli $\mathbf{S}^{+}$and $\mathbf{S}^{-}$, in the global orientation tuning profile, or in both. Measurements of relative orientation preference demonstrated significant effects in 27 cells $(31 \%)$, all in favor of the positively reinforced orientation $\left(\mathbf{S}^{+}\right)$. Modifications of orientation selectivity (studied over the entire orientation spectrum in $\mathbf{4 5}$ of the conditioned cells) usually consisted ( 21 out of 25 modified cells) of a competitive reorganization of the orientation tuning curve: the preferred orientation shifted toward $\mathbf{S}^{+}$, and a loss of relative visual responsiveness was observed for orientations close to the negatively reinforced orientation $\left(\mathbf{S}^{-}\right)$. The largest changes were found in deprived kittens at the peak of the critical period, although the probability of inducing a significant change studied during the first year of postnatal life was independent of age.

These functional modifications demonstrated at the cellular level are analogous to those induced by a global manipulation of the visual environment, when only a restricted spectrum of orientations is experienced during the critical period. Our results support the hypothesis that covariance levels between pre- and postsynaptic activity determine the sign and the amplitude of the modification of efficacy of cortical synapses.

\footnotetext{
Received Mar. 7, 1991; revised Oct. 31, 1991; accepted Nov. 5, 1991.

This work was supported by grants from the CNRS (AIP85-06931), MRES (84C1307 and 87C0187), and HFSP to Y.F., and from the CEC (B.R.A.I.N.ST2J0416) to Y.F. and E.B. D.S. was supported by the Cino del Duca and SingerPolignac Foundations during his doctoral studies. We thank Drs. Henry Kennedy and Nicole Ropert for helpful comments, Dr. Kirsty Grant for help with the English, and Michèle Gautier for technical assistance.

Correspondence should be addressed to Dr. Yves Frégnac, Laboratoire de Neurobiologie et Neuropharmacologie du Développement, Bât 440, Université Paris XI, F-91405 Orsay Cedex, France.

a Present address: Institut des Neurosciences, Université Paris VI, Paris F-75230, France.

b Present address: ESPCI, 10 rue Vauquelin, 75005 Paris, France.

Copyright (C) 1992 Society for Neuroscience $0270-6474 / 92 / 121280-21 \$ 05.00 / 0$
}

This article is the first of two companion articles describing cellular analogs of visual cortical plasticity, each devoted to a particular visual cortical receptive field property. These experiments are aimed at producing functional changes similar to those occurring during normal or abnormal visual development, while recording from a single neuron in cat area 17 [Frégnac et al., 1988; Shulz and Frégnac, 1992 (companion article)]. The present article focuses on orientation selectivity and demonstrates the role of temporal correlation between pre- and postsynaptic activity in the plasticity of this property.

\section{Population analysis of the plasticity of orientation selectivity}

Visual cortical cells are best activated by slits of light/dark bars or edges of appropriate orientation and position in the receptive field. Since the first report of such orientation-selective cells in visually inexperienced 8 -d-old kittens by Hubel and Wiesel (1963), the early postnatal development of orientation selectivity has been the subject of considerable attention. In 6-weekold normally reared kittens, most visual cortical cells are highly selective and all orientation preferences are represented (Blakemore and Van Sluyters, 1975; Frégnac and Imbert, 1978; Albus and Wolf, 1984), but this high level of functional specificity contrasts with the absence of orientation selectivity in kittens of the same age dark-reared from birth (Imbert and Buisseret, 1975; Leventhal and Hirsch, 1977; Frégnac and Imbert, 1978). Nevertheless, a few hours of visual experience given at that age to previously deprived kittens induces a level of specification in receptive field properties comparable to that observed in normally reared littermates (Imbert and Buisseret, 1975). Such evidence for fast functional changes at the peak of the critical period was one of the major motivations for the present experiments aimed to look for "acute" modifications that can be induced once the network has stabilized, possibly by imposing changes in the coupling gains between neuronal elements through activity-dependent processes.

The rapid increase in visual experience sensitivity during the first postnatal weeks explains the success of the protocols of restricted visual exposure (Blakemore and Cooper, 1970; Hirsch and Spinelli, 1970; but see also Stryker et al., 1978; Rauschecker and Singer, 1981): comparison of orientation preference of cortical cells recorded before and after a few sessions of daily exposure for a few hours to striped environments of fixed orientation showed the induction of a significant bias of representation in favor of the orientation to which the kittens had been exposed. Two different interpretations concerning the processes involved in these effects have been proposed, based on selective versus instructive mechanisms. While the results of Blakemore and Cooper (1990) are consistent with the idea of a massive reor- 
ganization of cortex and of a "capture" of the exposed orientation, the results of Hirsch and Spinclli (1970) could also bc explained by a silencing or degenerative process that specifically affected cells whose preferred orientations were not experienced by the animal. However, in view of the inherent limitations of the "population analysis" methodology - which is based on the comparison of distributions of receptive field properties established in different animals - no definitive conclusion could be drawn.

\section{A theoretical scheme of synaptic plasticity: the covariance hypothesis}

The experimental data suggesting that visual cortical functional specificity is shaped by activity-dependent processes have been taken as indirect support for Hebb's postulate, which posits that synaptic transmission is enhanced following an increase in temporal correlation between pre- and postsynaptic activity (Hebb, 1949). This clementary rule of synaptic plasticity predicts the reinforcement in the visual responsiveness of cortical neurons to experienced orientations (Rauschecker and Singer, 1981; reviewed in Frégnac and Imbert, 1984). However, Hebb's principle in a literal interpretation assumes only positive changes, that is, increases of synaptic efficacy of excitatory connections. This eventually leads to the undesirable situation where all synapses in the network saturate; such a "trivial" end state cannot be construed as the synaptic basis for functional selectivity. The family of algorithms of synaptic plasticity introduced by Sejnowski in 1977 in the cerebellum (Sejnowski, 1977a,b), and later by Bienenstock and coworkers in visual cortex (Bienenstock et al., 1982), overcomes this problem. They are based on a common covariance rule (detailed in Table 1) embodying competition between active and silent synapses. The change in synaptic efficacy at time $t$ is assumed to be proportional to the covariation of pre- and postsynaptic activitics, that is, to the product of the departures of the instantaneous pre- and postsynaptic activities at time $t$ from their respective mean values (averaged over a given period preceding time $t$ ). It is implicitly assumed that there is a modification threshold for postsynaptic activity, above which potentiation occurs and below which synaptic depression occurs. This threshold can be made dependent nonlinearly on the average past activity of the cell ("floating threshold" in Bienenstock et al., 1982), which ensures global stability of the synaptic modification process. Covariance-based algorithms predict both increases and decreases in synaptic efficacy, thereby allowing the network connectivity state to converge to nontrivial states. Optimality of these rules of synaptic plasticity has been discussed in the context of associative memory models (Willshaw and Dayan, 1990).

\section{The cellular analog approach}

In order to best assess whether cortical cells do individually change their orientation preference or tuning following vision restricted to a fixed orientation, we devised an associative conditioning protocol in the anesthetized and paralyzed preparation. Our aim was to demonstrate plasticity during the time of recording of single cortical cells. The neuronal response was artificially reinforced during the presentation of one orientation $\left(\mathrm{S}^{+}\right)$and suppressed while presenting another orientation $\left(\mathrm{S}^{-}\right)$ through the same eye. This technique of differential pairing presents three advantages. The first two are dictated by specific predictions of the covariance hypothesis: (1) Alternating "high" and "low" levels of forced activity keeps mean cellular activity
Table 1. Predictions of the covariance hypothesis

$\begin{array}{lllll}\text { Presynaptic } & 1 & 0 & 1 & 0 \\ \text { Postsynaptic } & 1 & 1 & 0 & 0 \\ \text { Covariance level } & + & - & - & 0 \\ \text { Change in synaptic gain } & + & - & - & = \\ \text { Protocol } & \mathrm{S}^{+} & & \mathrm{S}^{-} & \end{array}$

The covariance between $X$ and $Y$ is defined as the mean value of the product $(X-\underline{X}) \cdot(Y-\underline{Y})$, where $X$ and $\underline{Y}$ are the mean values of $X$ and $Y$, respectively. Each activity process ( $X$, presynaptic; $Y$, postsynaptic) is a time series defined on a discrete time scale, taking values 0 or 1 . The pairing procedure imposes a specific pattern of pre- and postsynaptic activity, given by one of the four situations described in the first two rows. This "repeated" and "persistent" pattern of coactivity (Hebb, 1949) results in a maintained level of covariance (third row), which in turn defines a synaptic change according to the covariance hypothesis. According to the covariance scheme, synapses whose activation is repeatedly correlated with the firing of the target cell (first column) will be reinforced (as a result of positive covariance), whereas those that are predominantly silent at the time of postsynaptic firing (second column) will lose their efficacy (as a result of negative covariance). Moreover, a decrease in synaptic efficacy is also predicted in case of a repetitive failure of a synapse to trigger the firing of the postsynaptic cell (again a case of negative covariance, shown in the third column).

during pairing similar to that evoked in control observation periods. This situation avoids the fluctuations of the plasticity threshold predicted by the "floating threshold" model if mean activity was not kept constant. (2) The artificial increase or decrease of postsynaptic firing alters the postsynaptic term of the covariance rule and hence predicts the sign and amplitude of the synaptic change. The third advantage derives from the use of relative rather than absolute measurements to assess changes following conditioning: (3) The high temporal variability of evoked firing during recording sessions lasting several hours, and the possibility of nonassociative changes affecting cellular excitability and/or membrane potentials mean that simultaneous comparison of visually evoked responses for two different test stimuli should yield more reliable conclusions than the direct observation of absolute changes in responses to a single test stimulus (see also Carew et al., 1984). Note also that using a continuous parameter such as orientation allows one to study the generalization of the effect to stimuli different from those used during the pairing procedure.

The present article reports on long-term associative changes in orientation preference and orientation selectivity of kitten and cat visual cortical neurons.

Preliminary partial results have been published elsewhere (Frégnac et al., 1988).

\section{Materials and Methods}

Rearing conditions. Sixty-six animals from the laboratory breeding colony were used, among which 41 were normally reared, 6 were darkreared from birth to the time of recording, and 19 were dark-reared for a period of varied length ending at the time of recording. For the last group, the deprivation period started between the first and the seventh week of age, in most cases at 3 weeks of age, and lasted on average 4.5 weeks.

Surgical preparation. Cats, aged from 4 weeks to adulthood at the lime of recording, were anesthetized by intramuscular injection of Althesin (Glaxo; $1.2 \mathrm{ml} / \mathrm{kg}: 10.8 \mathrm{mg} / \mathrm{kg}$ alfaxalone and $3.6 \mathrm{mg} / \mathrm{kg}$ alfadolone acetate). After cannulation of the femoral vein and tracheotomy, anesthesia was maintained by continuous intravenous Althesin infusion $(3 \mathrm{mg} / \mathrm{kg} / \mathrm{hr})$. Following an initial observation period ( $1 \mathrm{hr})$ during which we checked for signs of discomfort from the preparation, animals were paralyzed by intravenous infusion of Flaxedil (gallamine triethiodide, $15 \mathrm{mg} / \mathrm{kg} / \mathrm{hr}$ ), which was added to the Althesin perfusion and supplemented with glucose and saline. Fxpired $\mathrm{pCO}_{2}$ levels were maintained between $3.8 \%$ and $4.2 \%$, and EKG was monitored throughout the ex- 
a

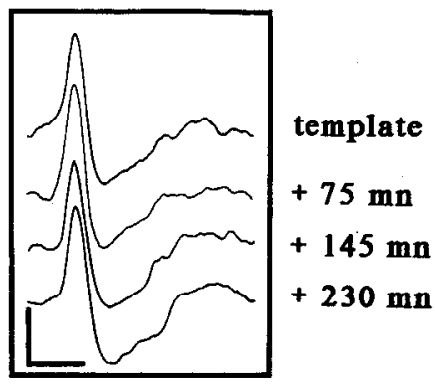

$\mathbf{C}$

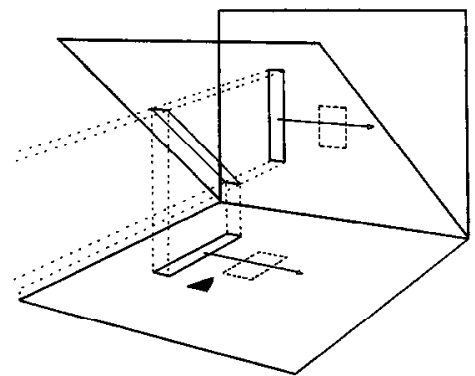

b

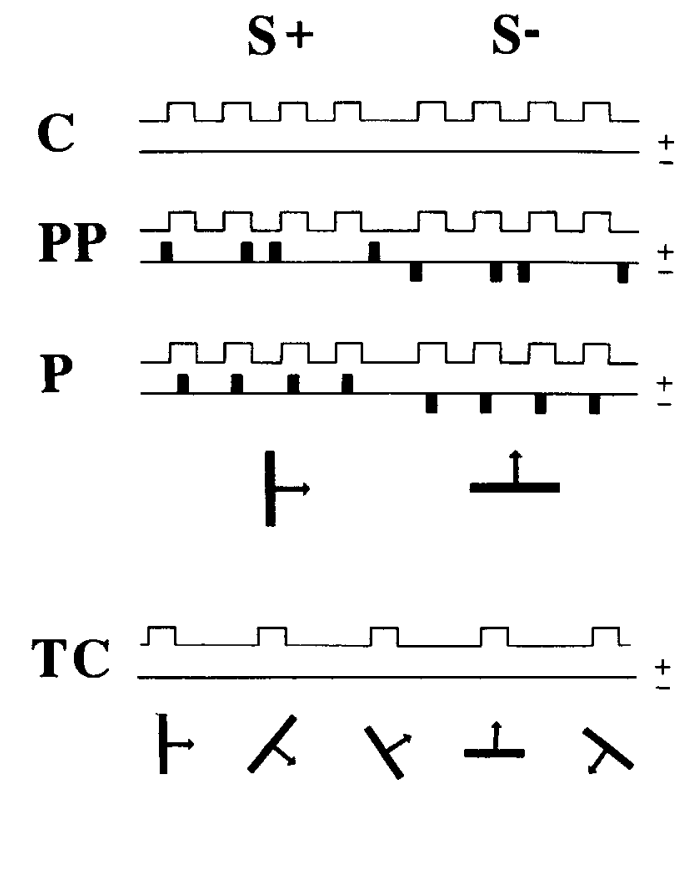

Figure 1. Protocols of imposed temporal correlation between orientation characteristics of the visual input and postsynaptic firing. $a$, For each recorded cell, action potential shape (calibration: $1 \mathrm{mV}, 1 \mathrm{msec}$ ) was continually monitored on a digital oscilloscope and compared to its initial template, in order to ensure that the same neuron was recorded throughout the experiment. $b$, Every square pulse in the upper lines indicates the temporal occurrence of a single visual stimulation (sweep of a slit of light with a fixed orientation across the receptive field), and every solid rectangle in the lower lines, the occurrence of an iontophoretic pulse of a given polarity (upward for positive, downward for negative). During controls (C), two visual stimuli ( $\mathbf{S}^{+}$, lefi column; $\mathbf{S}^{-}$, right column) of different orientations (e.g., vertical and horizontal) were presented monocularly (usually through the dominant eye) by blocks of four trials repeated in succession every 4-8 sec (upper line), without iontophoretic current (lower line). This elementary sequence was repeated 10-50 times. During pseudopairing $(P P)$, iontophoretic pulses of a fixed polarity for each stimulus were applied without correlation to the visual stimulation. During contiguous pairing $(P)$, iontophoretic pulses were applied together with the visual response, in such a way as to impose a significant increase (positive current, $\mathrm{S}^{+}$) or decrease (negative current, $\mathrm{S}^{-}$) of this response. In order to assess possible generalization of the effect to orientations other than those used during pairing, the orientation tuning curve (TC) was established before and after pairing, by presenting in a random order bars of different orientations in the absence of any iontophoretic current. In some cases, orientation tuning was in addition studied at different levels of constant iontophoretic current. $c$, During the differential pairing procedure, the temporal correlation between the orientation characteristic of a given stimulus entering the receptive field and the onset of the iontophoretic pulse controlling the postsynaptic firing was achieved using a semitranslucent screen oriented at $45^{\circ}$ that split the light beam and reflected it on a drawing table. Two photoelectric cells were positioned on the borders of the projected image of the receptive field $(\boldsymbol{\Delta})$, so that each was separately activated by only one of the two oriented stimuli used during pairing. The durations of the iontophoretic pulses were adjusted so as to restrict the control of activity to the period when the stimulus was in the receptive field.

periment. Body temperature was regulated at $38^{\circ} \mathrm{C}$. Nictitating membranes were retracted with Neosynephrine; pupils were dilated and accommodation was blocked with Atropine. Neutral contact lenses were used to protect the cornea from drying. Optical correction was assessed by retinoscopy (skiascopy) in kittens less than 8 weeks old and by reflection of direct tapetal illumination (Pettigrew et al., 1979) on the stimulation screen $(114 \mathrm{~cm})$ in older animals. The head was fixed in a stereotaxic Horsley-Clarke frame, and the skull was cemented to additional metallic bars, which significantly improved recording stability. Small holes were made bilaterally on the skull to expose area 17 in a region corresponding to the representation of the area centralis ( $\mathrm{L} 1-\mathrm{L} 2$, P1-P3; Tusa et al., 1978). At the end of recording, animals were killed by an intravenous injection of pentothal and perfused via the heart with Ringer's solution and 10\% formol in Ringer's solution. Cortical sections were stained with cresyl violet and examined for verification of the electrode placement in area 17 and in some cases for localization of the sites of extracellular injection of dye.

Extracellular recording, iontophoresis, and visual stimulation. Glass micropipettes (2-20 M , filled with $\mathrm{KCl}$, or $\mathrm{K}$-acetate, $3 \mathrm{M}$, supplemented with pontamine sky blue) were used to record extracellularly the activity of visual cortical neurons. Electrodes that showed any leak of potassium under microscope examination of the tip or that induced progressive increases in spontaneous activity during the first stages of recording were discarded. For each cell, the shape of the action potential (ranging in amplitude from 2 to $40 \mathrm{mV}$ above noise level) was continuously monitored and compared to its initial shape in order to ensure that the same neuron was recorded throughout the experiment (Fig. $1 a$ ). The recording electrode was also used as an iontophoretic channel through which currents of both polarities could be applied. Adjustment of bridge balance allowed uninterrupted recording of neuronal activity during iontophoresis (mean values were $-8 \mathrm{nA}$ for negative currents and +5 $\mathrm{nA}$ for positive currents). Preferred orientation, velocity, and direction of movement together with ocular dominance were estimated qualitatively by hand-held projection and back-projector stimulation. A semitranslucent screen oriented at $45^{\circ}$ was positioned behind the stimulation screen to intersect and split the light beams, so that the receptive field could be directly charted on a drawing table (Fig. $1 c$ ). After determining the optimal stimulation parameters, the orientation selectivity of the cell was quantitatively studied by a computer-driven presentation of a pseudorandom sequence of 30,12 , or 9 different orientations through the dominant eye. These three cases corresponded, respectively, to $12^{\circ}$, $30^{\circ}$, and $10^{\circ}$ intervals between two neighboring orientations and were chosen as a function of the initial estimate of the width of orientation tuning of the cell. The same sequence was repeated three to five times. 
In order to assess the initial relative preference between the two stimuli later used during the pairing procedure, these two test orientations were presented in blocks of eight trials (four for each orientation) until each had been presented at least 40 times. During the pairing procedure, the presentation of one of the two orientations (usually the nonpreferred one) was associated with an increase in discharge induced by the application of a positive current (ejection of $\mathrm{K}^{+}$ions; $\mathrm{S}^{+}$), while the presentation of the second orientation (usually the preferred one) was associated with a decrease or with a blockade of the visual activity induced by the application of a negative current through the recording electrode $\left(\mathrm{S}^{-}\right)$(see Fig. $1 b$ ). The synchronization of the iontophoretic action with the arrival of the stimulus in the receptive field was obtained by triggering photoelectric cells placed on the drawing table where the stimulus was partially reflected (see Fig. 1c). After pairing, the visual stimulation was repeated without the iontophoretic current (control stimulation) and a new orientation tuning curve was determined, in order to measure possible changes in orientation preference and selectivity. In half the cells studied, additional control measurements were interleaved to asscss possible nonassociative changes: (1) a quantitative study of the stability of the orientation tuning curve was performed at different levels and polarities of constant iontophoretic current, to ensure that basic properties such as orientation preference were independent of the level of polarization of the target neuron, and (2) a pseudopairing procedure was applied, in which the iontophoretic action (ejection and retention) was not correlated in time with the visual stimulation, although the two test orientations were associated with currents of the same polarities used during contiguous pairing.

Data analysis. An index of relative orientation preference (orientation bias ratio, or OBR)-defined as the normalized ratio of visual responses $\left[\mathbf{S}^{+} /\left(\mathbf{S}^{-}+\mathbf{S}^{+}\right)\right]$- was computed using a moving average technique (see Frégnac and Bienenstock, 1981). This normalized index equals 0 if a cell responds exclusively to the $S^{-}$stimulus and +1 if it only responds to the $\mathrm{S}^{+}$stimulus. In order to minimize biases due to progressive changes in the absolute level of firing, each integrated value of $\mathrm{S}^{+}$was compared with $S^{-}$values corresponding to trials just preceding and following the current one. This index was calculated on successive blocks of eight trials during both control and pairing periods, and the distributions of values established before and after pairing were compared statistically using parametric (unpaired Student's $t$ test, significance level of $p<0.005$ ) and nonparametric tests [Kolmogorov-Smirnov test (KS), significance level of $p<0.05$ ]. In order to assess the effectiveness of the pairing procedure on the cell activity, the OBR was also measured during pairing, which led to a three-category classification. If there was no significant change in OBR, the action of the pairing was termed "null." Conversely, if only one of the two types of pairings $\left(\mathrm{S}^{+}\right.$or $\mathrm{S}^{-}$) was effective, the action was considered "partial," and if modulation was achieved for both polarities, it was termed "completc."

Two additional measurements were derived from orientation tuning curves determined using stimuli not shown during pairing. First, tuningcurve areas were normalized to $100 \%$, and any reorganization in the orientation tuning was quantified by computing for each orientation the difference between the normalized response before and after pairing, thereby expressing relative gains and losses in visual responsiveness as a function of orientation. This computation was performed after the tuning curves - originally established on a $360^{\circ}$ scale - were folded over on a $180^{\circ}$ scale by summing responses obtained with opposite directions. Second, preferred orientation was assessed: the "center of gravity" of the peak was calculated by weighting three to five points around the preferred orientation with their respective firing frequencies.

The orientation selectivity of a cell was judged to be modified if at least one of two criteria was met: (1) a statistically significant change in OBR was observed when comparing control values after and before pairing, or (2) the area of the curve of differences between normalized responses after and before pairing exceeded $20 \%$ of the normalized area, and reorganization of tuning was accompanied by a shift of the preferred orientation. The second criterion was derived from previous studies on the intrinsic variability of orientation tuning responses (Frégnac and Bienenstock, 1981). By convention, the angular separation between the preferred orientations after and before pairing was termed "positive" if the peak of the tuning curve had shifted toward the $\mathrm{S}^{+}$orientation and "negative" if the shift was toward $S^{-}$or away from $S^{+}$. For cells showing initially no bias of direction or orientation yet becoming selective after pairing, the shift of peak was arbitrarily defined as twice the angular separation between the preferred orientation after pairing and the orientation halfway between $S^{+}$and $S^{-}$. The use of two criteria for mod- ification is justified by the fact that a cell deemed modified by criterion (1) may not change its preferred orientation and yet still reorganize its tuning profile by alterations in the polar asymmetry of the peak of response. Conversely, a cell may exhibit a significant change in the peak of response (criterion 2) without showing any significant change in the ratio of $\mathrm{S}^{+}$and $\mathrm{S}^{-}$responses.

\section{Results}

Two hundred and eighteen visual cells were recorded in area 17 , of which 94 were in normally reared kittens (4-15 weeks old), 85 were in partially deprived kittens ( $5-14$ weeks old), 36 were in juvenile cats (25-32 weeks old), and 3 were in normal $>1$-year-old adult cats. Ninety-seven of these cells were submitted to 159 differential pairing procedures and to $33 \mathrm{pscu}-$ dopairings. The other 111 cells were used for control recordings (temporal stability and dependency of receptive field properties on iontophoretic current).

\section{Iontophoretic control of neuronal excitability}

The efficacy of the iontophoretic control of activity was qualilatively studied during preliminary experiments on 290 cells (not included in Table 2). Seventy-nine percent of the cells (174 out of 221 tested) showed increased activity during the application of a positive current (and $\mathrm{K}^{+}$ion ejection), while $86 \%$ of the cells studied with a negative current ( 150 out of 175) showed decreased activity. In one case, a negative current ( $-1 \mathrm{nA})$ produced a significant increase in spontaneous activity. The relationship between discharge frequency and iontophoretic current intensity was studied quantitatively on 28 cells by using random current pulses (2-5 sec duration) of variablc polarity and amplitude with no visual stimulation. Spontaneous activity was continuously monitored in order to ensure that no consecutive effect on the global excitability level was present between the periods of iontophoresis. In all cases, pulses of positive current (less than $10 \mathrm{nA}$ ) produced very steep increases (within less than $50 \mathrm{msec}$ ) in activity, which returned within less than $200 \mathrm{msec}$ to its original level. Negative current reduced spontaneous activity in $57 \%$ of these cells and completely blocked it in $21 \%$ of additional cases.

The effects of positive currents applied through the $\mathrm{KCl} \mathrm{mi-}$ cropipette on the neuronal activity could result from an increased potassium concentration in the extracellular medium and/or from current per se. To distinguish these two possibilities, eight additional cells were recorded with double-barrel micropipettes (filled with $3 \mathrm{M} \mathrm{KCl}$ and $3 \mathrm{M} \mathrm{NaCl}$ ), which allowed current compensation through the $\mathrm{NaCl}$ barrel while ejecting $\mathrm{K}^{+}$ions through the $\mathrm{KCl}$ barrel. The activity of five of the six cells affected by the iontophoresis was increased to the same level during compensated and noncompensated conditions, suggesting that the activity changes result mainly from a potassiumdependent mechanism.

For cells submitted to differential pairing, iontophoretic control of firing was restricted to periods when the visual stimulus was in the receptive field (see Materials and Methods and Fig. 1c). In most cases, positive currents increased the level of firing without distorting the temporal pattern of the visually evoked poststimulus time histograms (PSTHs). Negative current application reduced visual as well as spontaneous activity. Furthermore, in cases of juxtacellular recording (spike amplitude, $>10 \mathrm{mV}$; polarity of the action potential similar to that of an intracellular record), it even suppressed evoked responses to the optimal stimulus (sce Figs. 4, 5a; sce also Shulz and Frégnac, 
a

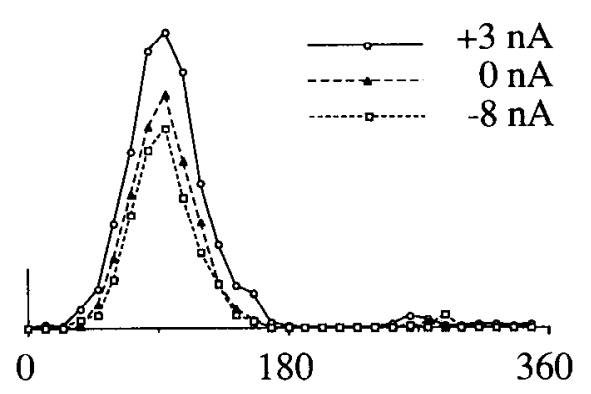

b

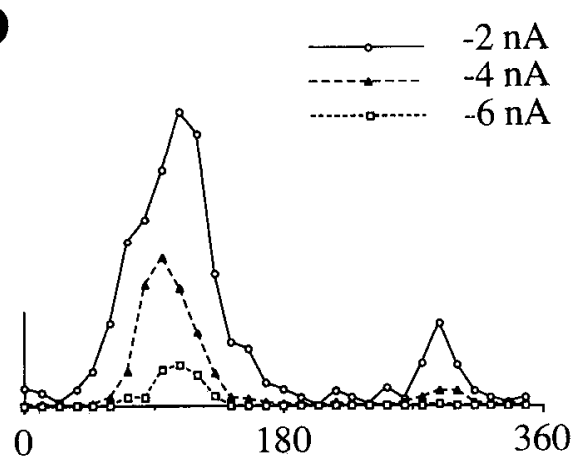

C
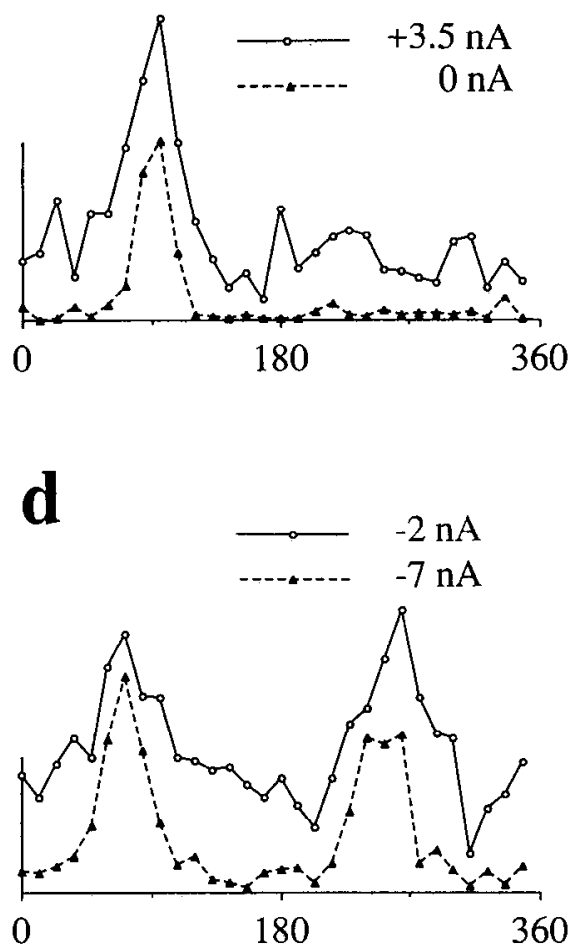

Figure 2. Invariance of orientation preference during constant current iontophoresis: recordings from four cells in area 17 of normally reared kittens. Each orientation tuning curve was obtained by presenting a random sequence of 30 orientations over $360^{\circ}$ (separated by steps of $12^{\circ}$ ). For each cell, mean tuning curves averaged over three to five runs for different levels of polarization of the recording $\mathrm{KCl}$ electrode are superimposed. Current levels were adjusted to relatively low values (less than $\pm 10 \mathrm{nA}$ ) so that they predominantly affected visual activity and left spontaneous activity essentially unchanged. Vertical calibration: $a-c, 10$ action potential (a.p.)/sec; $d, 5$ a.p./sec. $a$, The orientation preference shown by this cell, recorded in a 9-week-old kitten, was remarkably stable with time (data not shown) and independent of the level of iontophoretic current, which ranged from $-8 \mathrm{nA}$ (resulting in a $17 \%$ decrease in mean visual activity) to $+3 \mathrm{nA}$ (producing a $50 \%$ increase when compared with the 0 $\mathrm{nA}$ control level). $b$, For this other cell, recorded in a 13-week-old kitten, the mean level of response imposed by the $-4 \mathrm{nA}$ and the $-6 \mathrm{nA}$ currents was, respectively, $67 \%$ and $93 \%$ less than that observed with the $-2 \mathrm{nA}$ level. In spite of the differences in overall activity, the orientation tuning profile remained unchanged, whereas the directional asymmetry appeared to be reduced for more positive levels of current: a noticeable increase of response was unmasked for the direction of movement opposite to the preferred one. $c$, This cell, recorded in a 13-week-old kitten, was highly selective without current. Application of a $+3.5 \mathrm{nA}$ current produced a $510 \%$ increase in mean visual activity. Even at this high activation level, the preferred orientation remained unchanged. $d$, Bidirectional cell recorded in a 9-week-old kitten. The increase of the constant retention current from $-2 \mathrm{nA}$ to $-7 \mathrm{nA}$ reduced the overall activity by $62 \%$ without any change in the preferred orientation.

1992, Fig. 3), suggesting a hyperpolarizing field effect on membrane potential (Eccles, 1966). In most cases, the effect of current on visual responsiveness appeared to result from the direct control of the postsynaptic membrane potential.

\section{Temporal stability of orientation preference}

The temporal variability of the orientation tuning curve and of the relative preference between the two orientations used during pairing (given by the OBR; see Materials and Methods) was analyzed in 190 cells. Forty-five of these cells were studied quantitatively for periods of one to several hours. Control data in orientation-selective cells, recorded in both kitten and adult, confirm that both the preferred orientation (Henry et al., 1973; Hammond et al., 1975; Frégnac, 1982) and the general profile of the orientation tuning (Frégnac and Bienenstock, 1981) are remarkably stable using interleaved stimulation in the anesthetized and paralyzed preparation. Conversely, nonselective cells in visually deprived kittens are much more variable (Frégnac and Bienenstock, 1981; Frégnac, 1982). The directional asymmetry seen for certain receptive fields seemed less stable, even in normally reared kittens and adult cats (Frégnac, 1982), and spontaneous reversals of preferred direction were occasionally observed.

\section{Invariance of orientation preference at different levels of imposed iontophoretic current}

A second possible source of variability results from the use of extraneously applied current and from the induction of high transient concentrations of $\mathrm{K}^{+}$or $\mathrm{Cl}^{-}$in the extracellular medium. A constant leak of $\mathrm{K}^{+}$ions occurring from the microelectrode tip at zero current (Purves, 1981) could affect the orientation tuning (but see Materials and Methods). To exclude this possibility, the stability of orientation tuning and OBR was quantitatively assessed on 25 cells at levels and polarities of imposed current (mean values, $-8 \mathrm{nA}$ and $+5 \mathrm{nA}$ ) similar to those used during pairing, except that here they were applied permanently. Moreover, if there was a change in excitability after pairing, a constant current could be applied so as to impose a spontaneous activity level comparable to that before pairing.

In contrast to a number of other visual response properties 
Table 2. Summary of pairing experiments

\begin{tabular}{|c|c|c|c|c|c|}
\hline & \multicolumn{4}{|c|}{ Rearing condition } & \multirow[b]{3}{*}{ Total } \\
\hline & \multicolumn{3}{|c|}{ Normally reared } & \multirow{2}{*}{$\begin{array}{l}\text { Deprived } \\
\text { Kitten } \\
<15 \mathrm{w}\end{array}$} & \\
\hline & $\begin{array}{l}\text { Kitten } \\
<15 \mathrm{w} \\
\end{array}$ & $\begin{array}{l}\text { Juvenile } \\
21-32 w\end{array}$ & $\begin{array}{l}\text { Adult } \\
>1 \text { year }\end{array}$ & & \\
\hline Number of pseudopairings & 7 & 6 & - & 20 & 33 \\
\hline Number of cells & 7 & 5 & - & 20 & 32 \\
\hline Number of modified cells & $0(0 \%)$ & $0(0 \%)$ & - & $1(5 \%)$ & $1(3 \%)$ \\
\hline Number of pairings & 57 & 24 & 5 & 73 & 159 \\
\hline Number of cells & 35 & 11 & 3 & 38 & 87 \\
\hline Number of modified cells & $12(34 \%)$ & $7(64 \%)$ & $1(33 \%)$ & $15(39 \%)$ & $35(40 \%)$ \\
\hline
\end{tabular}

w, weeks.

such as absolute level of firing, directional asymmetry, and to a lesser extent ocular dominance (see Shulz and Frégnac, 1992), the preferred orientation appeared remarkably stable at different polarization levels. The main effect was an increase in the width of the tuning curve with more positive currents, sometimes accompanied by an unmasking of subliminal responses, whereas the preferred orientation remained constant even with responses five times larger than in the absence of iontophoretic current (Fig. 2). Conversely, negative current reduced tuning width. Thus, the effects of constant current application on orientation selectivity were similar to those reported to occur spontaneously over a several-hour period ("iceberg effect" in Frégnac and Bienenstock, 1981); in all cases, orientation preference remained invariant despite more or less "homothetic" transformations of the orientation tuning curve.

\section{Modifications of orientation selectivity induced by differential pairing}

This stability of orientation selectivity observed during continuous current application contrasted with the profound changes induced by a differential control of activity dependent on stimulus orientation. One hundred and fifty-nine pairing procedures and 33 pseudopairing procedures were carried out on 97 visual cortical cells. Table 2 shows the distribution of pairings and pseudopairings as well as the percentages of modified cells as a function of age and rearing conditions. While $40 \%$ of the cells (kitten, juvenile, and adult cat data being pooled together) submitted to at least one pairing procedure were modified in a significant way, only $3 \%$ showed significant changes following pseudopairing in which the iontophoretic action was not correlated with visual stimulation.

A change in relative orientation preference for a cell recorded in a 28 -d-old normally reared kitten is illustrated in Figure 3. This cell was monocular and initially orientation selective. A first pairing procedure, involving the repeated presentation of an initially nonpreferred orientation associated with the application of a positive current through the recording electrode $\left(\mathbf{S}^{+}\right)$, resulted in a potentiation of the response to this nonpreferred orientation. No significant change in response was found for the orientation associated with a negative current $\left(\mathbf{S}^{-}\right)$. This effect was replicated with a second pairing procedure, resulting in a further increase of response to the "reinforced" orientation, which, however, did not result in a full reversal of preference from $\mathrm{S}^{-}$to $\mathrm{S}^{+}$. To exclude the possibility of a nondifferential increase of response masked at $\mathrm{S}^{-}$by a saturation effect, we compared orientation tuning curves recorded before and after each pairing. This showed that the maximal response did indeed shift to an orientation intermediate between $\mathrm{S}^{-}$and $\mathrm{S}^{+}$(see Fig. $6 b$ ). Despite a modest shift in the preferred orientation, the modification in tuning profile shown by this cell definitely did not belong to the normal range seen with spontaneous variability. In particular, significant responses appeared following pairing for stimuli orthogonal to the initially preferred orientation, which were unable at the start of the experiment to evoke any suprathreshold response at all. In addition, the changes appear to be strongly dependent on the test orientation, as can be assessed from the normalized difference graph.

Similar findings were made in the visually deprived kitten. The cell illustrated in Figure 4 and recorded at the peak of the critical period showed a highly significant modification of relative orientation preference, resulting from a potentiation of the response to the $\mathrm{S}^{+}$orientation and a long-lasting depression of the response to the $S^{-}$orientation. Before pairing, the maximal response was found for the vertical orientation, and a small but significant response was obtained for the horizontal orientation. After repeated association of the vertical orientation with a blockade of the visual response $\left(\mathrm{S}^{-}\right)$, alternated with the association of the horizontal orientation with an artificially increased response $\left(S^{+}\right)$, the relative orientation preference reversed in favor of $\mathrm{S}^{+}$, with a complete loss of response for the initially preferred orientation. Despite an increase in spontaneous activity, the effect was still present $110 \mathrm{~min}$ after the end of the pairing and the OBR showed no recovery, even though the absolute level of response to the $\mathrm{S}^{+}$stimulus was slightly less than just after the pairing period.

Comparable changes in relative orientation preference in kitten cortex were found in $37 \%$ of the cells submitted to differential pairing (see Table 2). This high level of plasticity, revealed in the anesthetized and paralyzed preparation, contrasts with the absence of effects following the uncorrelated application of visual stimulation and current pulses (pseudopairing). This observation demonstrates that temporal contiguity is required in this conditioning procedure: the simultaneous activation of afferent terminals (evoked by visual stimulation) and of the postsynaptic neuron (by iontophoresis) is necessary for functional changes to occur. This requirement is further illustrated in the cell shown in Figure $5 a$ : pseudopairing affected neither its relative orientation preference nor the absolute levels of response for the paired stimuli, yet contiguous pairing-using the same current values-induced a long-lasting depression of the response to $\mathrm{S}^{-}$. The cell in Figure $5 b$ showed no significant effect following pseudopairing, but the contiguous pairing procedure, which imposed a strong nondifferential increase of both responses $\left(\mathrm{S}^{+}\right.$and $\left.\mathrm{S}^{-}\right)$, induced a long-lasting nondifferential po- 


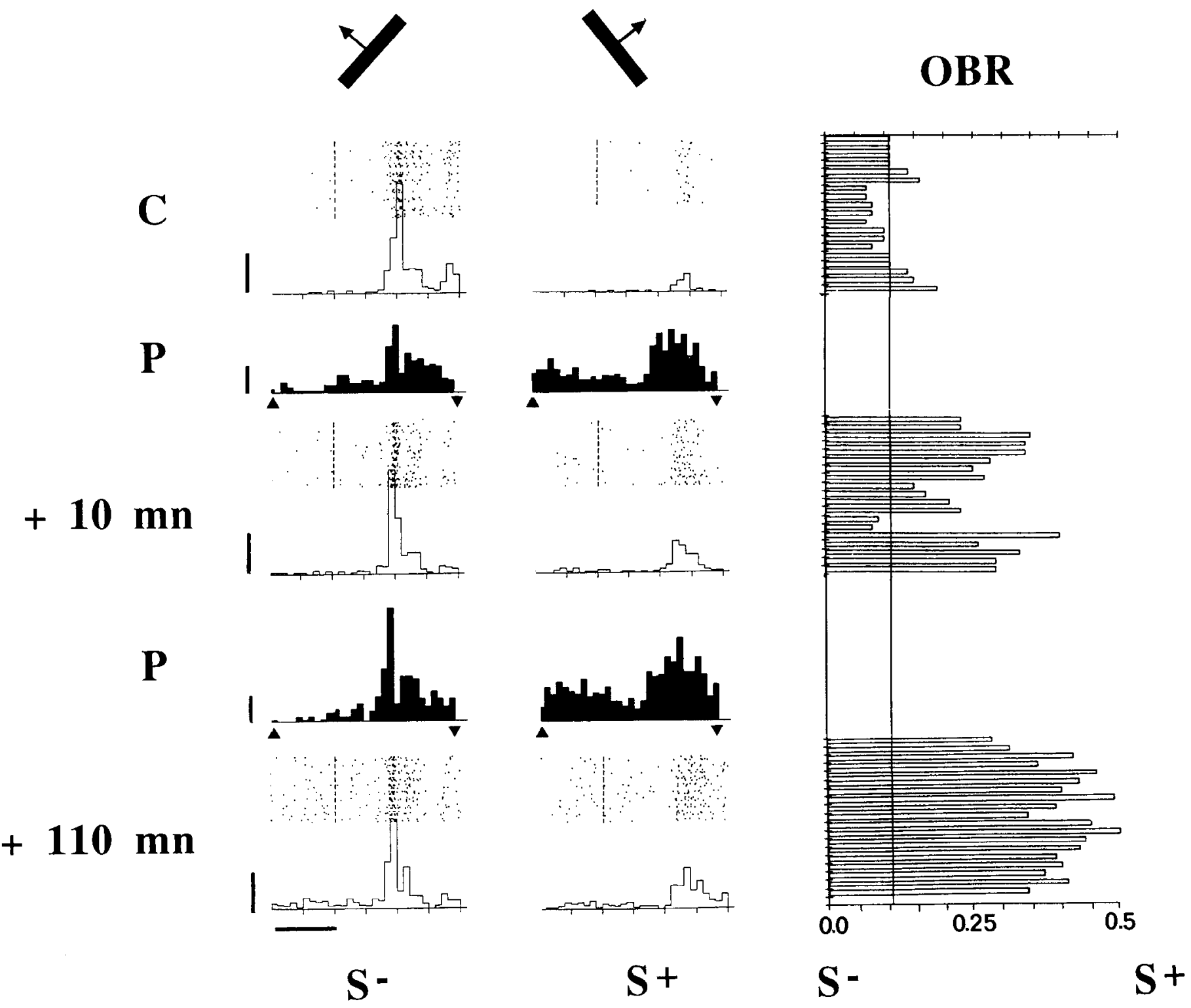

Figure 3. Long-lasting change of relative orientation preference during the critical period, in a normally reared kitten: recordings from a cell in area 17 of a 4-week-old normally reared kitten. Two similar pairing procedures induced a shift of the relative orientation preference of the cell toward the stimulus paired with a high level of activity $\left(\mathbf{S}^{+}\right)$. This effect was still present $2 \mathrm{hr}$ after pairing. The left two columns of PSTHs represent the visual responses to a moving bar of light of two different orientations (left column, $45^{\circ}$; center column, $135^{\circ}$ ). Dot displays superimposed on the open histograms correspond to responses observed for sequential individual trials: each line represents a single visual stimulation following a $1.5 \mathrm{sec}$ spontaneous activity period, and each point in this line represents the occurrence of one action potential. The vertical broken line indicates the onset of the visual sweep. Before pairing $(C)$ the cell responded preferentially to the $45^{\circ}$ orientation (left). During the first pairing procedure $(P$, solid histograms) the presentation of the $135^{\circ}$-oriented stimulus was associated 50 times with an $8.5 \mathrm{nA}$ positive current pulse, which resulted in an enhancement of the visual response. In alternation, the presentation of the initially preferred orientation $\left(45^{\circ}\right.$ orientation, center) was paired with a $-1.5 \mathrm{nA}$ negative current pulse, which significantly reduced the visual response. Solid triangles indicate the onset (upward) and offset (downward) of iontophoresis. Ten minutes after the first pairing procedure, the response to the positively reinforced orientation was significantly increased, and this effect was further amplified after a second pairing procedure $\left(\mathrm{S}^{+},+4 \mathrm{nA} ; \mathrm{S}^{-},-1.5 \mathrm{nA}\right)$. Calibration: vertical, 10 a.p./sec; horizontal, $1 \mathrm{sec}$ and $2.5^{\circ}$. The temporal evolution of the $O B R\left[\mathrm{~S}^{+} /\left(\mathrm{S}^{+}+\mathbf{S}^{-}\right)\right]$, calculated by a moving average technique on four pairs of successive stimulations and corresponding to the sequential analysis of each row of the PSTIIs, is shown in the right column. The initial mean value of the OBR (control value) is indicated by the vertical line $(0.110 \pm 0.008)$. After the first pairing procedure (which imposed a mean ratio of $0.737 \pm$ 0.013 ), the orientation preference was significantly modified toward the reinforced orientation (OBR $=0.252 \pm 0.020 ; \mathrm{KS} p<0.007$ ). After a second pairing procedure (imposing a mean OBR of $0.675 \pm 0.018)$, a further shift in relative preference (OBR $=0.401 \pm 0.013 ; \mathrm{KS} p<0.012)$ was obtained. The differential changes in the responses to the test stimuli (decrease for $\mathrm{S}^{-}$, increase for $\mathrm{S}^{+}$) cannot be explained by the progressive but moderate increase in spontaneous activity level.

tentiation of both responses in the control recordings. The response pattern shown by the cell for at least $90 \mathrm{~min}$ following pairing resembled very much that imposed during iontophoresis. This striking long-term potentiation (LTP) cannot be due to a mere increase in spontaneous activity, since this latter progressively diminished during and after pairing (see Fig. 5 caption).

Functional changes were not restricted to the stimuli pre- 

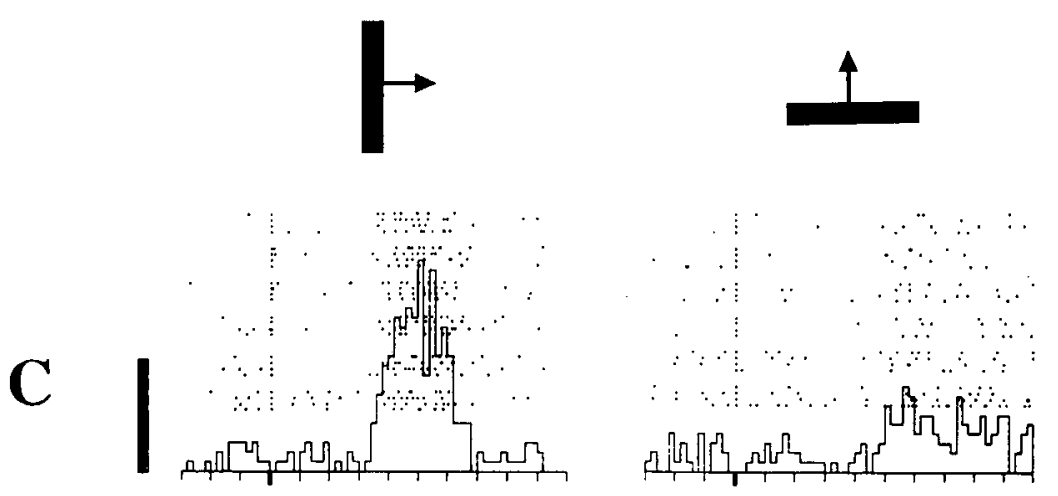

\section{$+10 \mathrm{mn}$}
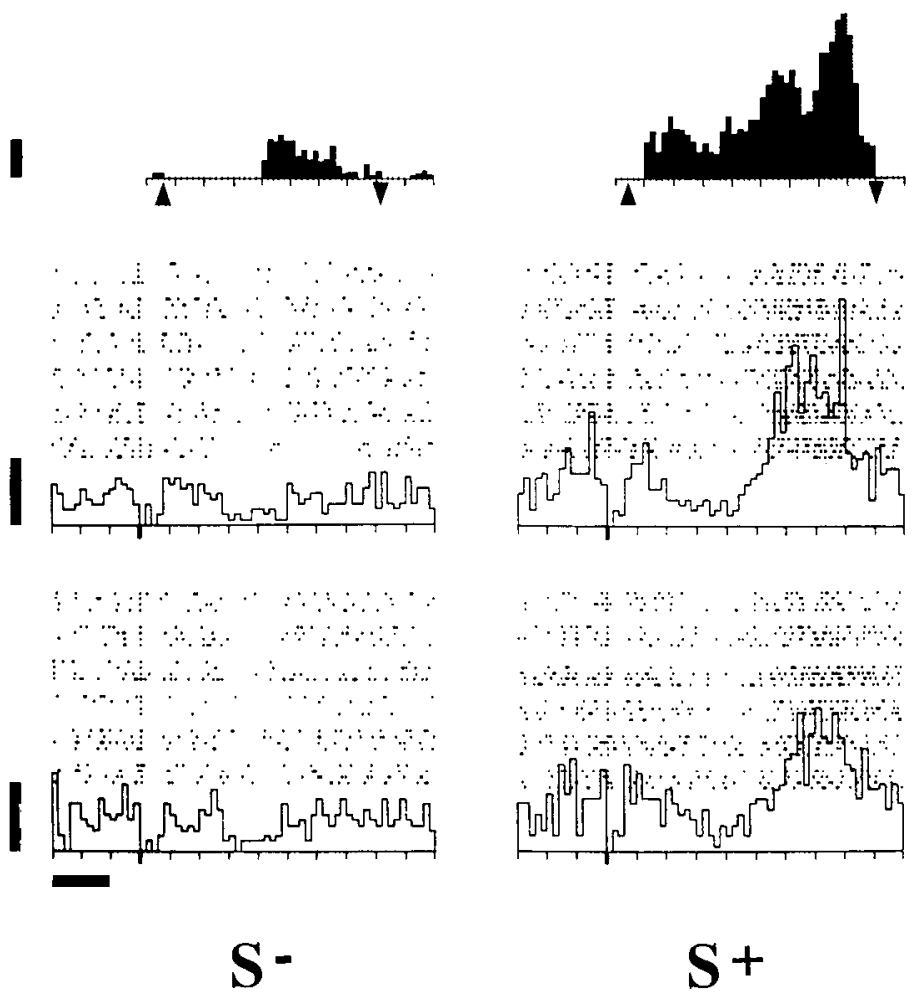

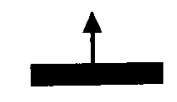

OBR

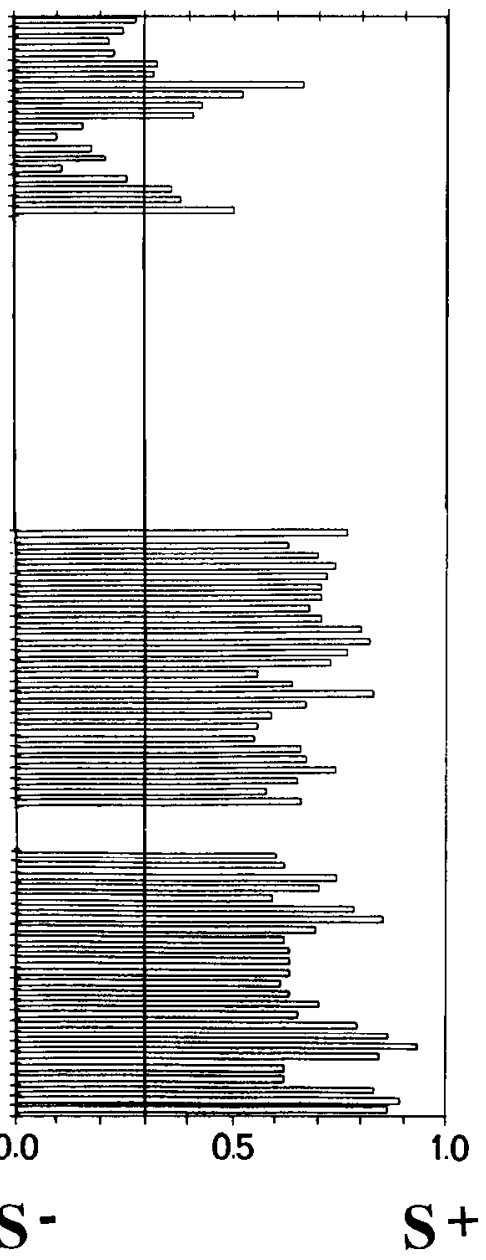

Figure 4. Long-lasting change of relative orientation preference during the critical period in a visually deprived kitten: recordings from a cell in area 17 of a 5-week-old kitten reared in darkness for the 3 weeks preceding the experiment. Pairing resulted in a shift of preference between two orientations: a long-lasting suppression of the visual response was observed for the initially preferred (vertical) orientation, which had been associated with a blockade of synaptic firing, and a long-lasting increase in the response for the (horizontal) orientation, associated with a reinforcement of the activity during pairing. PSTHs represent visual responses to a moving bar (left column, vertical orientation; center column, horizontal orientation; same conventions as in Fig. 3). The cell exhibited an initial orientation bias for a vertical stimulus $(C)$. During pairing $(P$, solid histograms), a positive current pulse $(+3 \mathrm{nA})$ was applied when the horizontal bar was shown, and interleaved with a negative current pulse (-7 nA) when the vertical bar was presented. Current pulses produced an enhancement of the visual response for the initially nonpreferred stimulus, and a progressive blockade of postsynaptic activity for the initially preferred stimulus. Blockade was complete at the end of the pairing procedure $\left(60 \mathrm{~S}^{+}\right.$and $\mathrm{S}^{-}$ associations). A dramatic change in orientation preference was observed immediately after pairing and was still present for 110 min after the end of the pairing procedure (lower row). Calibration: vertical, 5 a.p./sec; horizontal, $1 \mathrm{sec}$ and $1.5^{\circ}$. The right column represents the temporal evolution of the OBR (see Fig. 3 for details) in the three control periods: before pairing $(C)$ and $10 \mathrm{~min}$ and 110 min after pairing. The vertical line represents the mean value of the OBR calculated for the initial control period $(C)$. The orientation bias, initially in favor of the $S^{-}$orientation, shifted significantly after pairing toward the $\mathrm{S}^{+}$orientation (KS $\left.p<0.005\right)$, and this effect was maintained 110 min afterward (KS $\left.p<0.005\right)$.

sented during pairing: generalizations of the effect, revealed by studying the orientation tuning curve, were also observed. Figure 6 shows tuning curve modifications for the cclls whose associative-pairing histories are presented in Figures 3 and 4. The first cell (Fig. $6 a$ ), recorded in a partially deprived 5-week-old kitten, provides a particularly striking example. It initially preferred vertical orientations $\left(90^{\circ}, \mathrm{S}^{-}\right)$, but after pairing, it became exclusively tuned to the orientation associated with the high level of discharge $\left(180^{\circ}, \mathrm{S}^{+}\right)$. The second example (Fig. $6 b$ ) was recorded in a normally reared 4-week-old kitten and shows a much more limitcd shift of its preferred orientation toward $\mathrm{S}^{+}$ ( $15^{\circ}$ as compared to the $90^{\circ}$ difference between $S^{+}$and $S^{-}$). However, significant responses appear following pairing, for stimuli orthogonal to the initially preferred orientation, which failed at the start of the experiment to evoke any suprathreshold response. In addition, the changes appear strongly dependent on 


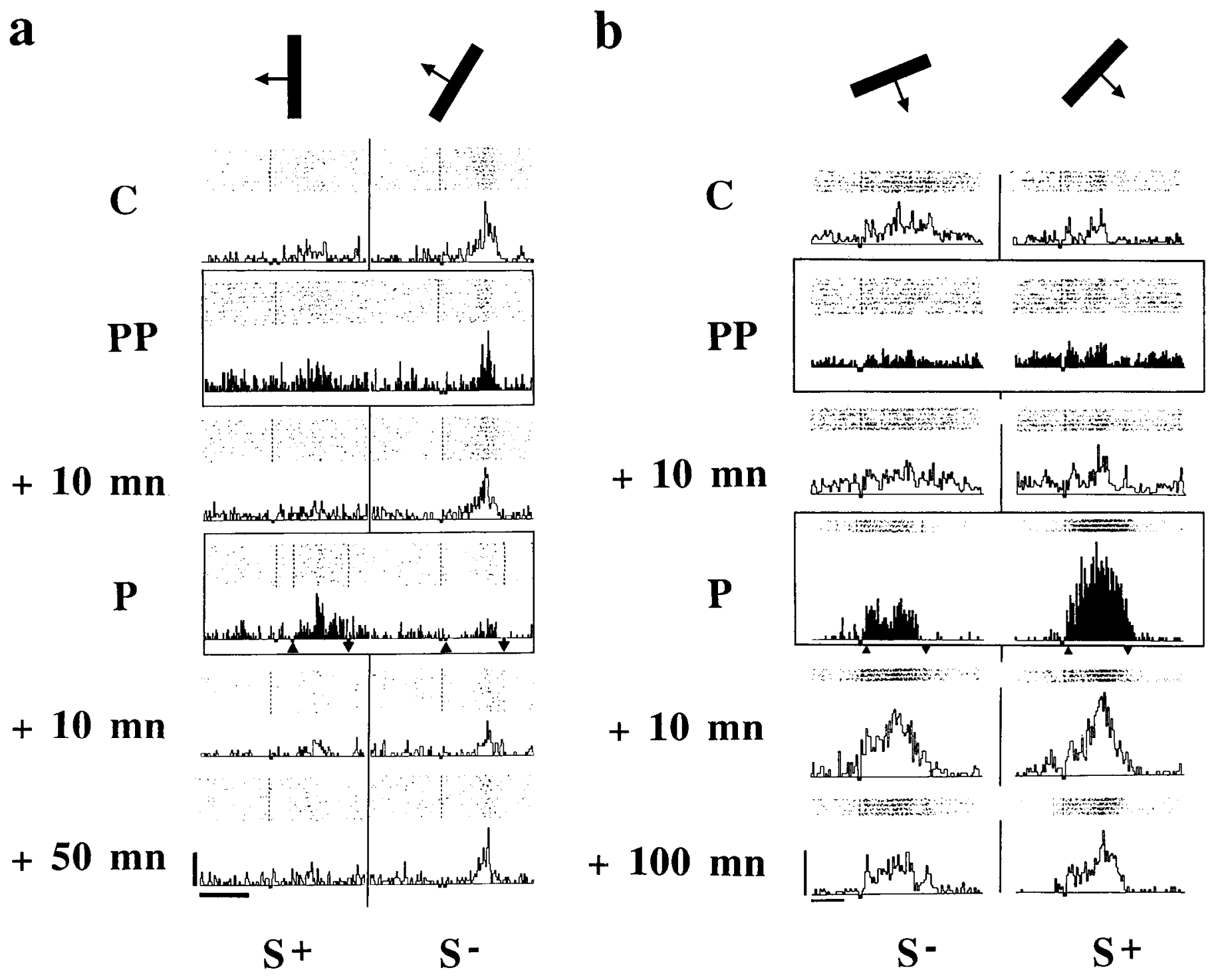

Figure 5. Temporal contiguity requirements: comparative effects of pseudopairing and pairing procedures. $a$, Recordings from a cell in area 17 of a 32-week-old normally reared cat (same conventions as in Fig. 3). The cell, studied for $2 \mathrm{hr} 45 \mathrm{~min}$, was submitted before pairing to a pseudopairing procedure $(P P)$, during which current pulses lasting $1.2 \sec$ (constant retention current, $-5 \mathrm{nA} ; \mathrm{S}^{+},+2 \mathrm{nA} ; \mathrm{S}^{-},-2 \mathrm{nA}$ ) were randomly applied (40 presentations). No noticeable change was observed 10 minutes afterward (OBR before PP, $0.321 \pm 0.020 ;$ OBR after PP, $0.302 \pm$ $0.020 ; \mathrm{KS} p>0.37$ ). During the subsequent pairing ( $P$, same current levels, polarity, and duration as during PP), current pulses were applied simultaneously with the sweep of the visual bar across the receptive field, imposing a reversal in the relative preference for the two orientations (OBR during pairing, $0.803 \pm 0.014$; KS $p<0.001$ ). A significant trace of this effect was maintained 10 min afterward in the absence of any iontophoretic current (OBR after pairing, $0.436 \pm 0.018 ; \mathrm{KS} p<0.026$ ) and was due to a long-lasting reduction of the response for the $\mathrm{S}^{-}$orientation, which returned to its initial level $50 \mathrm{~min}$ later (OBR $=0.346 \pm 0.027$, extinction; KS $p>0.208$ ). Calibration: vertical, 10 a.p./sec; horizontal, 1 sec and $6.5^{\circ} . b$, Cell recorded in area 17 of a 15-week-old normally reared kitten and held for more than 3 hr. Since it initially showed strong binocular facilitation, all PSTHs were constructed under binocular viewing conditions (using Risley prisms for receptive field superimposition). A nonassociative procedure ( $P P ; 1.5 \mathrm{sec}$ pulses of $-6 \mathrm{nA}$ and $+14 \mathrm{nA}$, respectively; 40 presentations for each polarity) did not change the response of the cell (OBR before PP, $0.347 \pm 0.021$; OBR after PP, $0.436 \pm 0.038 ; \mathrm{KS} p>0.318$ ). During contiguous pairing $(P)$, the same current pulses were applied simultaneously with the visual stimulus. For this particular cell, and in contrast with what was observed in all other cases, the negative current pulses paired with the $30^{\circ}$ orientation $\left(\mathrm{S}^{-}\right)$imposed an increase and a more structured visual response compared to the control period. In alternation, the $60^{\circ}$ orientation $\left(\mathrm{S}^{+}\right)$was paired with a $+14 \mathrm{n \Lambda}$ current that also induced a strong increase of the visual response $(\mathrm{OBR}=0.72 \pm$ $0.01, \mathrm{KS} p<0.047$ ). Following this contiguous nondifferential pairing, the cell showed a long-lasting increase in visual responsiveness for both test orientations and the pattern of activity appeared remarkably similar to that imposed during the associative procedure. Both responses to $\mathrm{S}^{+}$ and $\mathrm{S}^{-}$orientations were potentiated, and this effect was maintained to a lesser extent 100 min afterward $(\mathrm{OBR}+10 \mathrm{mn}, 0.498 \pm 0.008, \mathrm{KS} p<$ $0.060 ; \mathrm{OBR}+100 \mathrm{mn}, 0.509 \pm 0.015, \mathrm{KS} p<0.025$ ). Calibration: vertical, 20 a.p./sec; horizontal, 1 sec and $4.3^{\circ}$.

the test orientation as can be assessed from the normalized difference graph. Forty minutes after the end of the pairing procedure, the preferred orientation returned to its initial value $\left(60^{\circ}\right)$, although the increase in the response to $\mathrm{S}^{+}$was still present.

As mentioned in the introductory remarks, a major devel- opmental question left unsolved by most studies of the maturation of orientation selectivity in cortex is what functional kinetics are responsible for the emergence of orientation preference. This problem, indirectly tackled by population analysis techniques (Frégnac, 1979a), can be addressed directly at the single- 
$\mathbf{a}$

\section{BEFORE PAIRING}

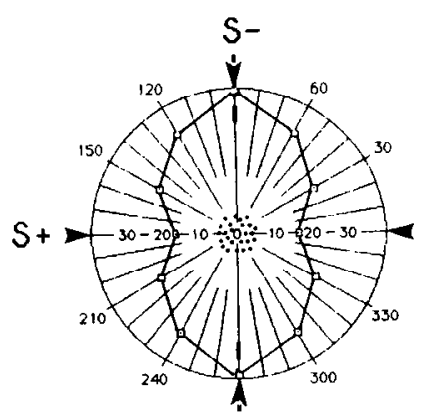

AFTER PAIRING

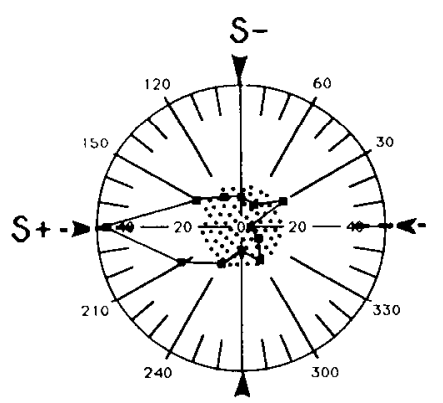

NORMALIZED
DIFFERENCE

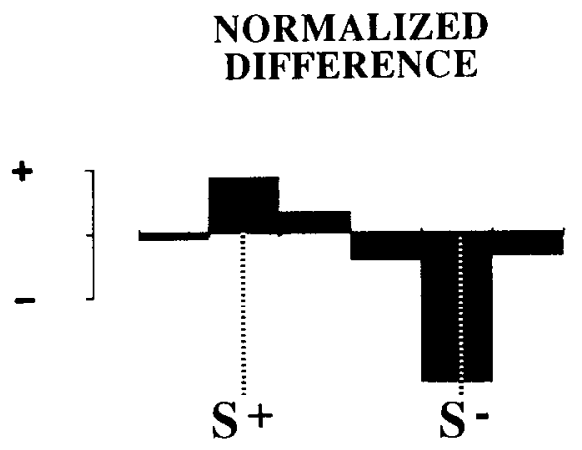

b

\section{BEFORE PAIRING}

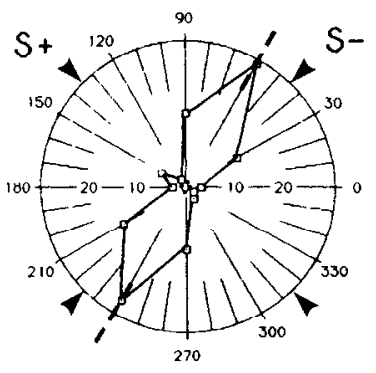

AFTER PAIRING

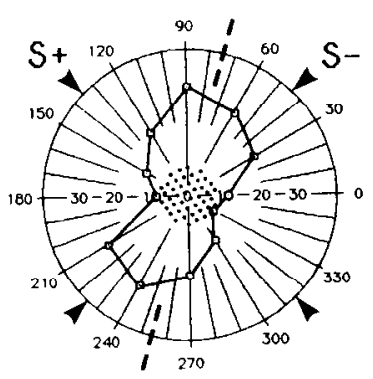

EXTINCTION

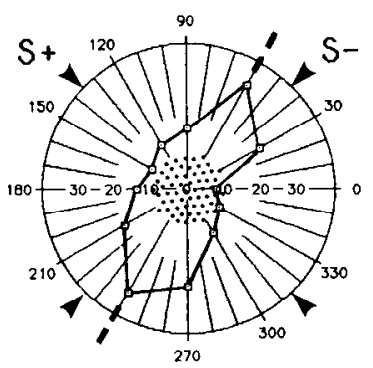

\section{NORMALIZED DIFFERENCE}

Figure 6. Generalization gradients-orientation selectivity changes during the critical period: recordings from two cells in area 17 of a 5 -weekold partially deprived kitten $(a)$ and a 4-week-old normally reared kitten $(b)$. The analysis of the OBR and the evolution of responses for the orientations shown during the pairing proccdure werc presented for these two cells in Figures 4 and 3, respectively. Polar orientation tuning curves were established before pairing (control, upper row) and after pairing (middle and bottom rows) over a $360^{\circ}$ range (with steps of $30^{\circ}$ ) by randomized motion of bars across the receptive field, averaged over three to five runs. The distance of each radius from the center indicates the cumulated number of spikes elicited by the sweep of the oriented bar in a given direction. The mean level of spontaneous activity is shown by the stippled area. The directions and orientations used in the pairing procedure are indicated by the arrowheads and the $S^{+} / S^{-} s y m b o l s$. The broken line indicates the preferred orientation (see Materials and Methods). The differences between the normalized tuning curves before and after pairing (folded on a $180^{\circ}$ scale) are presented as histograms (see Materials and Methods) of gains (positive) and losses (negative) expressed as a function of the orientation of the test stimulus. $a$. This cell was initially responded to all orientations. Responses for $\mathbf{S}^{+}$and $\mathbf{S}^{-}$orientations were averaged over 80 presentations during control runs, and the initial tuning curve was interpolated for intermediate orientations. During pairing (see Fig. 4 for details), alternating presentations of a vertical $\left(90^{\circ}\right)$ and a horizontal $\left(180^{\circ}\right)$ orientation were associated, respectively, with a low and a high level of response. After pairing, systematic exploration of the receptive field over the whole range of possible orientations (with steps of $30^{\circ}$ ) showed that the cell had become tuned to the positively reinforced orientation; the response to the vertical orientation was depressed. The change in orientation tuning was selective for both orientation and direction of movement of the oriented bar used in the pairing procedure (i.e., $180^{\circ}$ ). The difference between the normalized tuning curves indicates a selective gain $(+)$ in responsiveness centered around $\mathbf{S}^{+}$and a loss $(-)$centered around the $\mathbf{S}^{-}$orientation. Calibration of normalized differences, $\pm 20 \% . b$. This cell was initially sclective to orientation and bidirectional, preferring the $60^{\circ}$ orientation. During the first pairing procedure (see Fig. 3 for details), the $135^{\circ}$ and $45^{\circ}$ orientations were associated, respectively, with "high" and "low" levels of response. After this pairing procedure, the cell showed a shift of $15^{\circ}$ in its preferred orientation toward the $S^{+}$stimulus together with an enlargement of the tuning and an increase in spontaneous activity. Differences between the normalized tuning curves after correction for spontaneous activity changes, shown in the right column, show a selective increase of the responsiveness for $\mathrm{S}^{+}$and a loss for $\mathrm{S}^{-}$. Calibration, $\pm 10 \%$. This effect appeared to be linked mainly to the orientation characteristic of the paired stimuli, since it did not affect the bidirectionality of the cell. Forty minutes after the second pairing procedure (see Fig. 3 for details), the preferred orientation shifted back to its initial value (i.e., $60^{\circ}$; see EXTINCTION). The normalized difference histogram facing each tuning curve, established by comparison with the control tuning (upper row), shows the reversibility of the changes over time. 
cell level during the time course of conditioning protocols such as ours (see Fig. 7). For cells initially weakly biased or nonselective to orientation and recorded either in normally reared kittens or, to a greater extent, in kittens deprived of visual experience, the differential pairing procedure resulted in the induction of a new orientation preference. The cell in the right panel of Figure 7, recorded from a 35-d-old dark-reared kitten, initially showed a similar response for the two test orientations ( $60^{\circ}$ for $\mathrm{S}^{+}$and $120^{\circ}$ for $\mathrm{S}^{-} ; \mathrm{OBR}=0.533 \pm 0.010$ before pairing). Pseudopairing (not shown) induced no significant functional change. After contiguous pairing, the cell became orientation selective; that is, it had no response to stimuli orthogonal to the preferred orientation. A strong directional asymmetry developed in favor of the $\mathrm{S}^{+}$orientation, corresponding to a maximal response centered only $12^{\circ}$ from $\mathrm{S}^{+}$. In contrast, an almost complete depression of the visual response was observed for the $\mathrm{S}^{-}$ orientation, calculated from the iterative stimulation control protocols (OBR $=0.795 \pm 0.03$ after pairing; KS $p<0.0035$ ). This effect was maintained for $105 \mathrm{~min}$, until the cell became again nonselective to orientation (data not shown). Such changes replicated in other cells demonstrate the capture of the visual response by the "reinforced" orientation.

Similar findings were observed in initially nonoriented cells recorded in normally reared kittens. The cell in the left panel of Figure 7 , recorded in a 12-week-old normally reared kitten, was one of the rare nonoriented cells encountered at that age. In the control period preceding pairing, equal responses were obtained for both $\mathrm{S}^{+}\left(90^{\circ}\right)$ and $\mathrm{S}^{-}\left(0^{\circ}\right)$ orientations $(\mathrm{OBR}=0.511$ \pm 0.008 , calculated from the iterative protocol). After the associative-pairing procedure, the cell acquired an orientation preference centered on $84^{\circ}\left(6^{\circ}\right.$ from $\left.\mathrm{S}^{+}\right)$, and exhibited a significant long-lasting depression of the response to all other orientations including $S^{-}(\mathrm{OBR}=0.609 \pm 0.013$ after pairing; $\mathrm{KS}$ $p<0.003$ ).

This potential for plasticity was not restricted to the early phase of postnatal development during which maturation of this property occurs (see Frégnac and Imbert, 1984, their Fig. 2). Somewhat unexpected was the finding of significant changes in orientation preference several months after most cortical cells had acquired or expressed adultlike levels of specificity. Effects in kittens such as those shown in Figure $6 b$ revealing an incomplete adaptation of the tuning profile in the direction of the reinforced stimulus $\left(\mathrm{S}^{+}\right)$could also be induced in the juvenile and adult cortex, provided the orientations $\mathrm{S}^{+}$and $\mathrm{S}^{-}$were chosen within the initial range of responsiveness of the cell. In the cell presented in Figure $8 a$ and recorded in an adult cat, for which the angular separation between $\mathrm{S}^{+}$and $\mathrm{S}^{-}$was $24^{\circ}$, the preferred orientation shifted by $18^{\circ}$ toward the $\mathrm{S}^{+}$orientation after pairing (OBR before pairing, $0.275 \pm 0.009$; after pairing, $0.428 \pm 0.012$; KS $p<0.003$ ). A similar progressive shift in preferred orientation is illustrated in Figure $8 b$ for a neuron recorded in a 23-week-old normally reared juvenile cat. After the first pairing, a potentiation of the visual response developed around the preferred orientation $\left(198^{\circ}\right)$ and was more prominent near the $\mathrm{S}^{+}$stimulus (OBR before pairing, $0.352 \pm 0.009$; after pairing, $0.429 \pm 0.007$; KS $p<0.005$ ). This significant change in relative orientation preference was accompanied by a slight shift $\left(6^{\circ}\right)$ of the preferred orientation toward $\mathrm{S}^{+}$. The generalized potentiation of visual responses disappeared after the sccond pairing, and a bimodal tuning curve emerged showing a second peak centered on the orientation associated with a high discharge level during pairing $\left(156^{\circ}, \mathrm{S}^{+}\right)$. Finally, after a third pairing, a depression of activity affected predominantly the $\mathrm{S}^{-}$- orientation, and the maximal response shifted by another $18^{\circ}$ toward $\mathrm{S}^{+}$. This sequence of changes in the preferred orientation demonstrates a progressive reorganization of orientation selectivity that fits with the competitive advantage imposed during the pairing procedures.

Orientation tuning was studied quantitatively on 45 cells, including two cells that were only submitted to pseudopairing. Among the other 43 cells, 27 (63\%) were modified (see Materials and Methods for criteria). Twenty-one of the modified cells $(48.8 \%)$ displaced their preferred orientation toward the $\mathrm{S}^{+}$stimulus, whereas only one cell $(2.3 \%)$ shifted toward $\mathrm{S}^{-}$. Four cells $(9.3 \%)$ showed no shift in preferred orientation, although their OBR was significantly affected following pairing. The remaining cell showed a massive depression of activity affecting mainly the $\mathrm{S}^{+}$and $\mathrm{S}^{-}$orientations but also intermediate ones (rendering meaningless the assessment of orientation shifts). If the tuning analysis was restricted to the two test stimuli (as is the case when using the iterative stimulation protocol), 19 of the "modified" cells $(44.1 \%)$ showed a competitive advantage for $\mathrm{S}^{+}$after pairing, against 1 cell $(2.3 \%)$ for the $\mathrm{S}^{-}$orientation. Seven cells showed no asymmetry or advantage for either $\mathrm{S}^{+}$or $\mathrm{S}^{-}$.

Statistical analysis of the gains and losses in orientation selectivity, obtained by subtracting the normalized tuning curves before and after pairing and plotted as a function of orientation (see Materials and Methods), indicates an almost systematic reorganization of the tuning profile in "modified" cells. The individual "normalized difference" curves (histograms) shown in Figures 6-8, as well as averaged modifications in tuning, computed from 26 "modified" cells (Fig. 9), demonstrate the coherence in the reorganization process: a gain in visual responsiveness centered around the $\mathbf{S}^{+}$orientation is accompanied by a loss in responsiveness centered around $\mathbf{S}^{-}$(Fig. 9, left; $\mathbf{S}^{+}$ $>\mathrm{S}^{-}$; KS $p<0.037$ ). In contrast, the 16 "nonmodified" cells showed no significant alteration of tuning (Fig. 9, right; $\mathbf{S}^{+}$not significantly different from $\mathrm{S}^{-}, \mathrm{KS} p>0.11$ ).

When a modification of the orientation preference was observed, it was almost always (95\% of cases) in favor of the $\mathrm{S}^{+}$ stimulus (Fig. 10a). The success rate of the conditioning procedure did not seem critically dependent on the angular separation between $\mathrm{S}^{+}$and $\mathrm{S}^{-}$, although the minimum separation used was $24^{\circ}$. This choice was justified a posteriori since the linear regression between the observed shift in orientation preference and the angular separation between $\mathrm{S}^{+}$and $\mathrm{S}^{-}$predicts an absence of modification for a $12^{\circ}$ separation (Fig. 10b). This value could be considered as the minimum separation necessary for efficient competition between $\mathrm{S}^{+}$and $\mathrm{S}^{-}$. The slope of the relationship appears also to be less than unity, indicating that on average the adaptation in orientation preference was incomplete. However, in $23 \%$ of the "modified" cells, the shift in orientation preference was equal in amplitude to that imposed during pairing.

We also studied the effect of the pairing procedure on the directional selectivity (conditioning protocols actually used only one direction of movement, orthogonal to stimulus orientation). Forty-four percent of the changes in orientation preference also affected directional asymmetry for the $\mathrm{S}^{+}$orientation (studied in 18 cells). In two cases, including that exemplified in Figure $8 a$, initially unidirectional cells became bidirectional after the associative procedure because of the unmasking of a new response for the direction of motion opposed to that of the $\mathrm{S}^{+}$ stimulus. In all other positive cases (see, e.g., Figs. $6 a ; 7$, de- 


\section{NORMAL}

\section{BEFORE PAIRING}

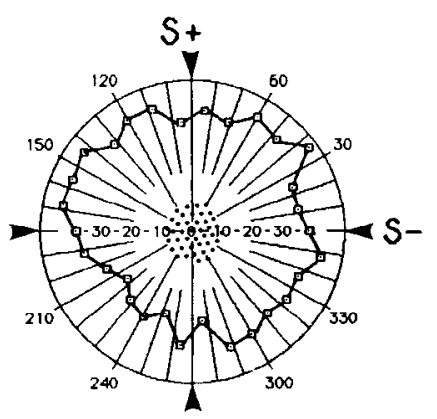

\section{AFTER PAIRING}
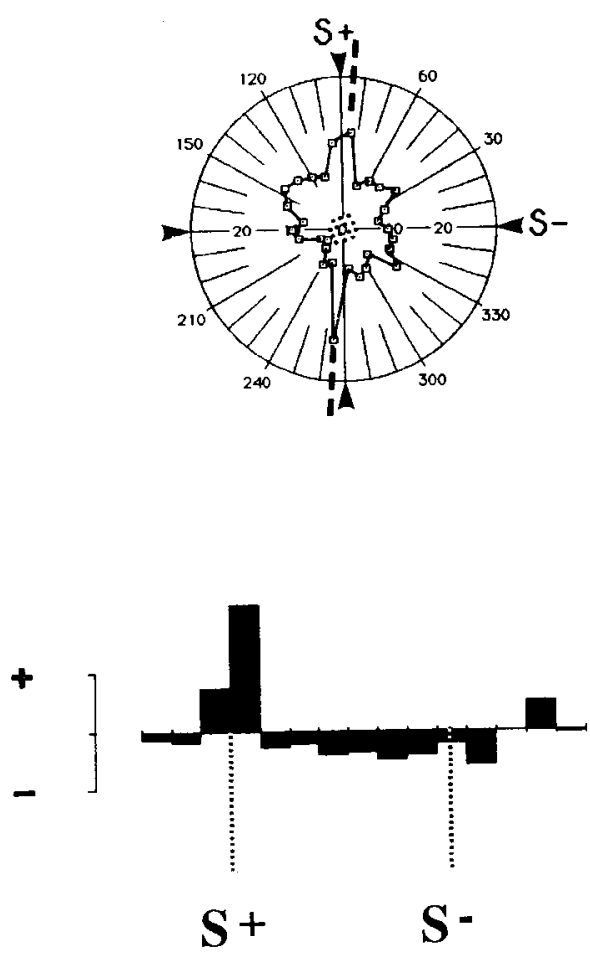

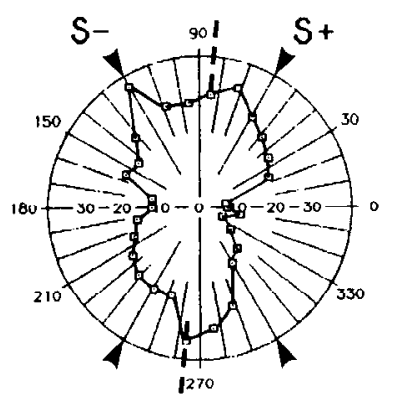

DEPRIVED
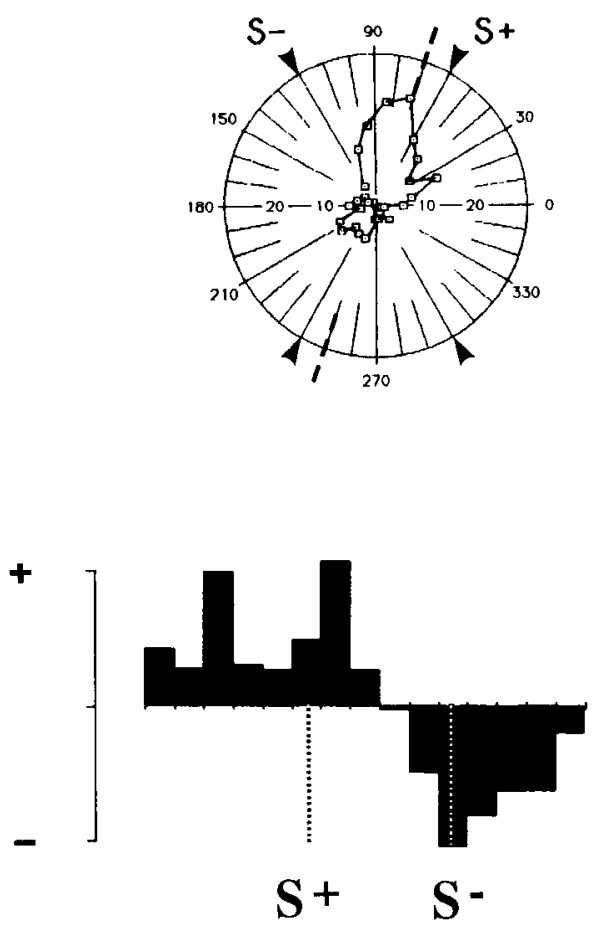

Figure 7. Acquisition of orientation preference in initially nonoriented cells, in normally reared and visually deprived kittens: recordings from two cells in area 17 of 5- and 12-week-old kittens submitted to different rearing conditions. Polar orientation tuning curves were established and repeated three times over a $360^{\circ}$ range (with steps of $12^{\circ}$ or $30^{\circ}$ ) by randomized motion of bars across the receptive field (see Fig. 6 for details). The bottom row represents the gains $(+)$ and losses $(-)$ of visual responsiveness given by the difference between normalized tuning curves after (middle row) and before (upper row) pairing, expressed as a function of orientation (on a $180^{\circ}$ scale). Calibration, $\pm 5 \%$. These cells, initially nonselective to orientation, acquired after pairing an orientation preference which was closely tuned to that of the stimulus paired with an increase in visual response $\left(S^{+}\right)$. NORMAL, Normally reared kitten. This cell, recorded for $2 \mathrm{hr} 30 \mathrm{~min}$ in a 12-week-old animal, was initially nonselective; the level of response was comparable for the $\mathrm{S}^{+}\left(90^{\circ}\right)$ and $\mathrm{S}^{-}\left(0^{\circ}\right)$ orientations. Two pairing procedures $\left(224\right.$ presentations of $\mathrm{S}^{+}$with a $+10.8 \mathrm{nA}$ current, interleaved with 224 presentations of $\mathrm{S}^{-}$with a $-2.6 \mathrm{nA}$ current) induced a bias in the tuning profile peaking near the $\mathrm{S}^{+}$orientation $\left(84^{\circ}\right)$, together with a significant decrease of the visual response for all other orientations including $\mathrm{S}^{-}$. The normalized difference histogram (bottom row) indicates a gain $(+)$ of responsiveness for the $\mathrm{S}^{+}$orientation and a loss $(-)$of responsiveness for almost all other orientations. DEPRIVED, Cell recorded for $3 \mathrm{hr} 10 \mathrm{~min}$ in a 5 -week-old dark reared kitten. After 40 presentations of $\mathrm{S}^{+}$paired with a $+4 \mathrm{nA}$ current, interleaved with 40 presentations of $\mathrm{S}^{-}$paired with a $-5.6 \mathrm{nA}$ current, the cell developed an orientation preference centered at $12^{\circ}$ only from $\mathrm{S}^{+}$. The significant change in relative preference between the two test stimuli in favor of $S^{+}$(iterative protocol, not shown), measured during the first hour following pairing (KS $p<0.002$ ), was correlated with the modification in the orientation tuning profile (shown here) established at the same time. Note, as in other cases, the increased responsiveness for $\mathrm{S}^{+}$and the loss of response for $\mathrm{S}^{-}$, shown in the normalized difference histograms (lower row). 
$\mathbf{a}$
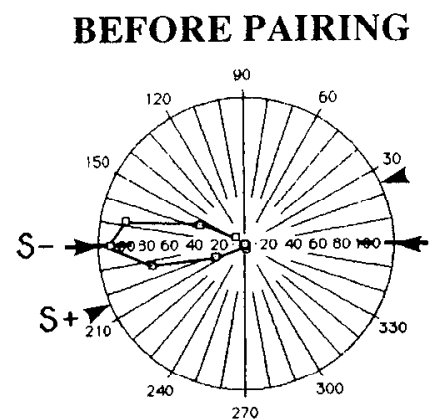

AFTER PAIRING

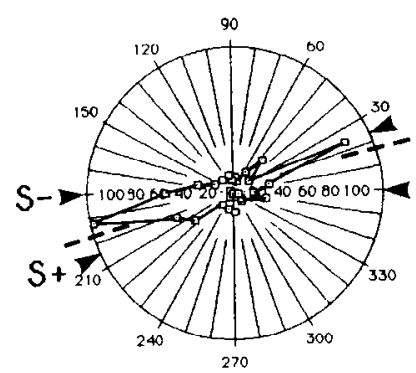

\section{NORMALIZED} DIFFERENCE

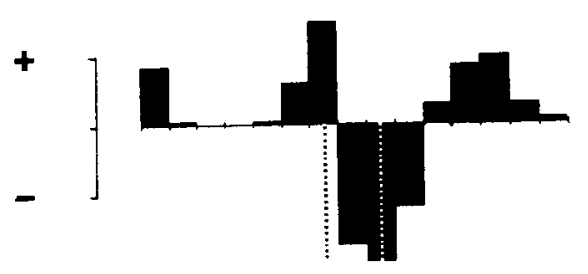

$\mathbf{S}+\mathbf{S}-$
D BEFORE PAIRING

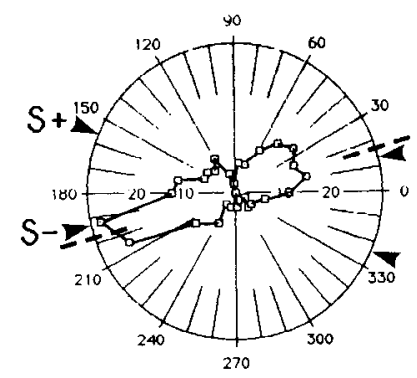

AFTER 1st PAIRING

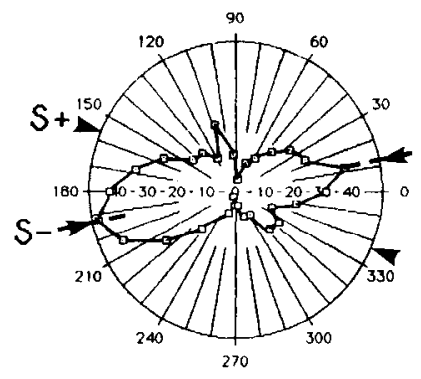

AFTER 2nd PAIRING
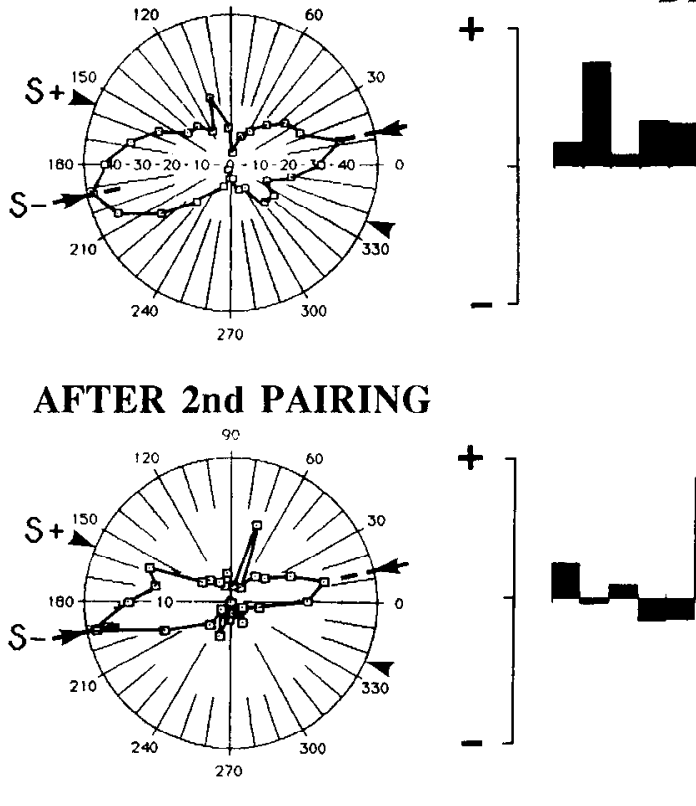

AFTER 3rd PAIRING

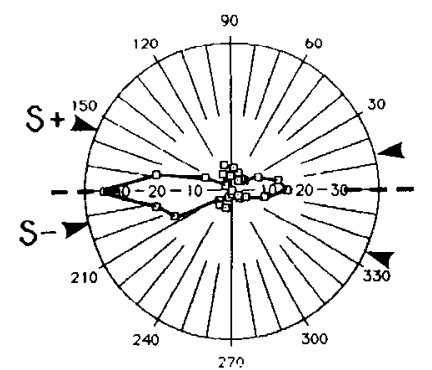

NORMALIZED
DIFFERENCE
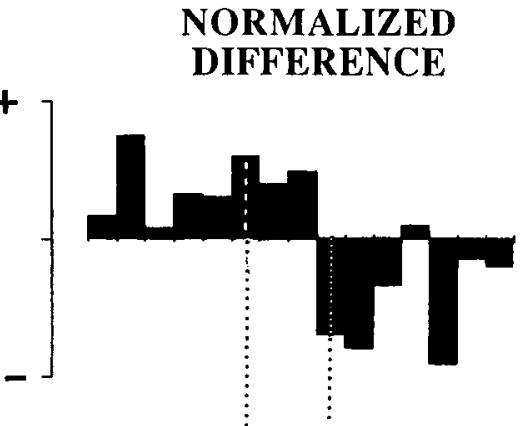

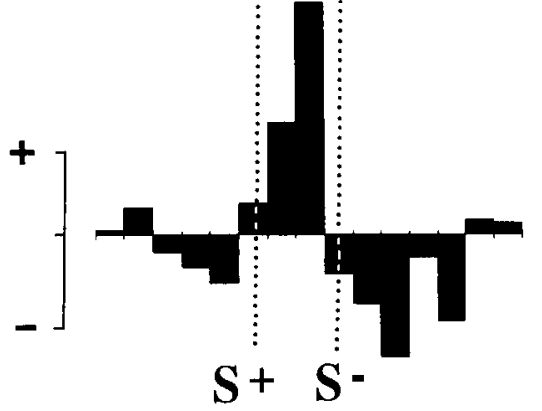

Figure 8. Orientation selectivity changes in juvenile and adult cat cortical neurons: recordings from two cells in area 17 of normally reared cats. These mature cells, initially selective to orientation, acquired after pairing a new orientation preference by shifting their tuning curves in the direction of the $S^{+}$orientation. Polar orientation tuning curves were established and repeated three times over a $360^{\circ}$ range (with steps of $12^{\circ}$ ) by randomized motion of bars across the receptive field (see Fig. 6 for details). Levels of statistical significance in the changes of the relative preferences (OBR) for the two test orientations ( $\mathrm{S}^{+}$and $\mathrm{S}^{-}$) were assessed by comparing series of 40 iterative runs before and after pairing (not shown). $a$, This cell, recorded for $1 \mathrm{hr} 15 \mathrm{~min}$ in an adult cat, showed $30 \mathrm{~min}$ after the pairing procedure ( 40 presentations of $\mathrm{S}^{+}$with a $+5 \mathrm{nA}$ current, interleaved with 40 presentations of $S^{-}$with a $-2.6 \mathrm{nA}$ current) a shift of $18^{\circ}$ in its preferred orientation toward $\mathrm{S}^{+}$, together with a significant loss of its directional asymmetry. The histogram shown below indicates a gain of responsiveness for the $\mathrm{S}^{+}$orientation and a loss of responsiveness centered around the $\mathrm{S}^{-}$orientation. A weak but significant level of response also appeared for orientations orthogonal to $\mathrm{S}^{-}$to which the cell did not respond initially. Calibration, $\pm 10 \%$. $b$, This cell, recorded for $4 \mathrm{hr} 20 \mathrm{~min}$ in a 23 -week-old normally reared cat, was submitted to three pairing procedures and showed a progressive clockwise rotation of its preferred orientation toward $\mathrm{S}^{+}$. Successive orientation tuning curves, established with a constant retention current of $-1 \mathrm{nA}$ before pairing and after each of the three pairings, are presented from top to bottom. All histograms (calibration, $\pm 5 \%$ ) shown on the right result from comparing the tuning curve shown in the same row to the initial control (top row). After a first series of 40 associations $\left(\mathbf{S}^{-},-1 \mathrm{nA} ; \mathbf{S}^{+},+11 \mathrm{nA}\right)$, the orientation tuning profile, although still centered around $\mathrm{S}^{-}$, exhibited a large change in polar asymmetry that resulted mainly from an increased responsiveness for orientations near $\mathrm{S}^{+}$(second row from top). After the second pairing procedure (40 associations of $\mathrm{S}^{+}$ and $\mathrm{S}^{-}$stimuli with $+1 \mathrm{nA}$ and $-2 \mathrm{nA}$ current pulses, respectively), the cell transiently showed an atypical bimodal tuning curve with a second peak emerging for the $\mathrm{S}^{+}$orientation (third row from top). Finally, a third pairing ( 40 presentations of $\mathrm{S}^{+}$with a $+2.5 \mathrm{nA}$ current and of $\mathrm{S}^{-}$with a $-9 \mathrm{nA}$ current) resulted in a total shift of $24^{\circ}$ from the initially preferred orientation toward the reinforced stimulus $\left(\mathrm{S}^{+}\right)$. 
MODIFIED

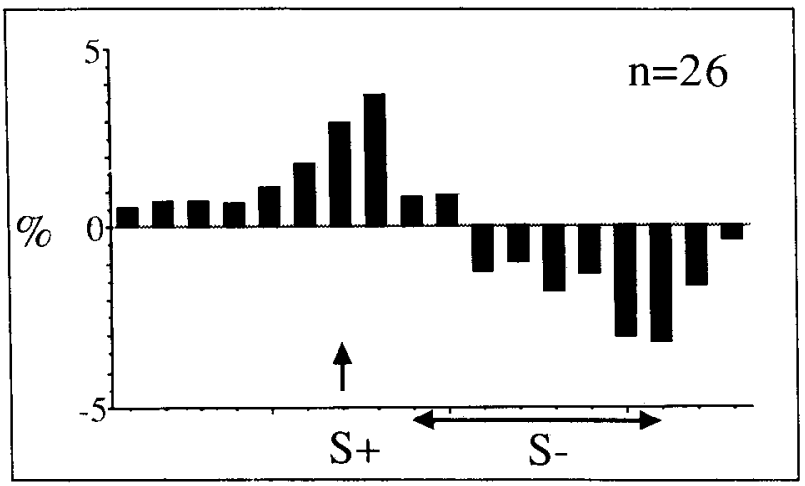

NON-MODIFIED

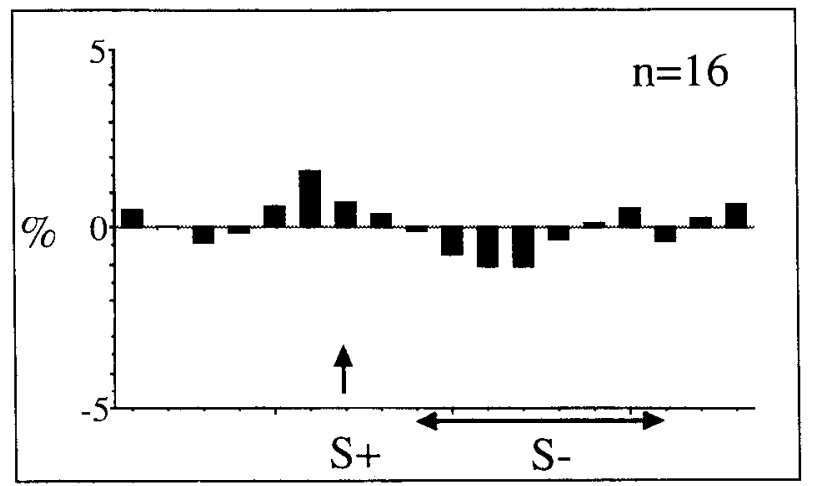

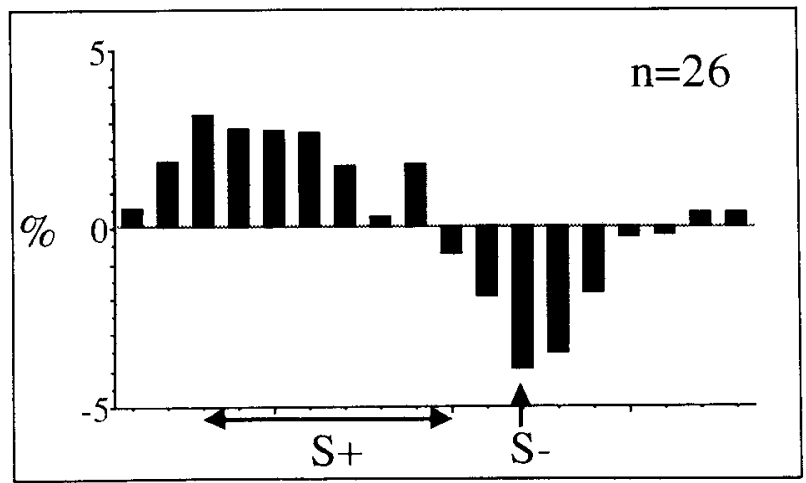

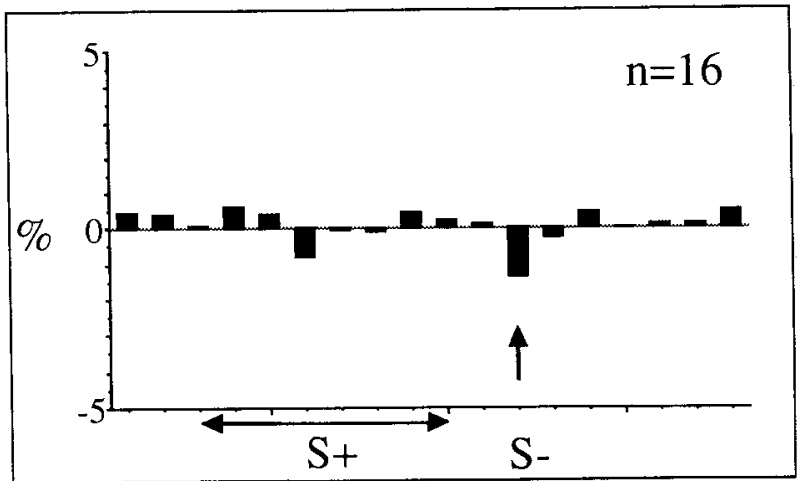

Figure 9. Differential potentiation and depression of orientation responses. These four graphs illustrate competitive changes in orientation tuning in "modified" versus "nonmodified" cells. A global "normalized difference analysis" was performed separately for the "modified" $(n=26)$ and the "nonmodified" cells $(n=16)$. In order to compare all tuning profiles irrespective of the angular step used in the measurements, orientation tuning curves were normalized and aligned on a common arbitrary orientation abscissa $\left(10^{\circ} \mathrm{step}\right)$. Missing values were then interpolated from adjacent observed values. After computing, for each cell and on the entire orientation spectrum, the algebraic difference between the normalized orientation tuning curves before and after pairing, the mean curve averaged within each group of cells ("modified" and "nonmodified") was plotted as a function of orientation (on a $180^{\circ}$ scale). Since the angular separation between the $\mathrm{S}^{+}$and the $\mathrm{S}$ orientations could differ from cell to cell (ranging from $24^{\circ}$ to $90^{\circ}$ ), the average normalized difference histograms were analyzed in two separate forms, all tuning curves being aligned either on the $\mathrm{S}^{+}$orientation (upper row) or on the $\mathrm{S}^{-}$orientation (lower row). Results shown in the left panels for the "modified" cells indicate that on average a gain in responsiveness developed after pairing in favor of the $\mathbf{S}^{+}$orientation and was accompanied by a loss of responsiveness centered on the $\mathbf{S}^{-}$orientation. In contrast, no significant change was observed in the "nonmodified" cell group [although a small bias is apparent due to cells showing partial effects that did not meet all the criteria required for significance (see Materials and Methods)].

prived), the response for the $\mathrm{S}^{+}$direction was preferentially reinforced following pairing. Induction of unidirectionality was even demonstrated in five neurons that were initially nonoriented or bidirectional.

\section{Activity dependence and time course of orientation selectivity changes}

The induction of functional modifications appeared to be strongly linked to the control of postsynaptic activity during the pairing procedure. The largest orientation changes were found in cells where iontophoretic action was "complete" (see Materials and Methods), that is, when both $\mathrm{S}^{+}$and $\mathrm{S}^{-}$pairings were effective in respectively increasing and reducing the rate of discharge. Fifty percent of cells changed their relative orientation preference in these pairing conditions, whereas only $42 \%$ of cells were modified when iontophoretic action had been "partial," that is, limited to either $\mathrm{S}^{+}$or $\mathrm{S}^{-}$. Note in both cases, however, that the shift in the relative preference between the two test stimuliwhenever it occurred-cannot be unambiguously attributed to a single iontophoretic action, since potentiation and/or depression of visual response changes could potentially result from homo- or heterosynaptic modifications. There was no evidence that the proportion of changes differs in adult and kitten cortex, or that it depends on the polarity of the iontophoretic current applied during pairing. These effects depended on the temporal contiguity of iontophoretic action, since they were generally absent following pseudopairing procedures. In the only case where a modification was found, iontophoresis significantly altered the OBR in favor of $\mathrm{S}^{+}$in spite of its lack of correlation with visual stimulation, and this bias was maintained after the 
$\mathbf{a}$

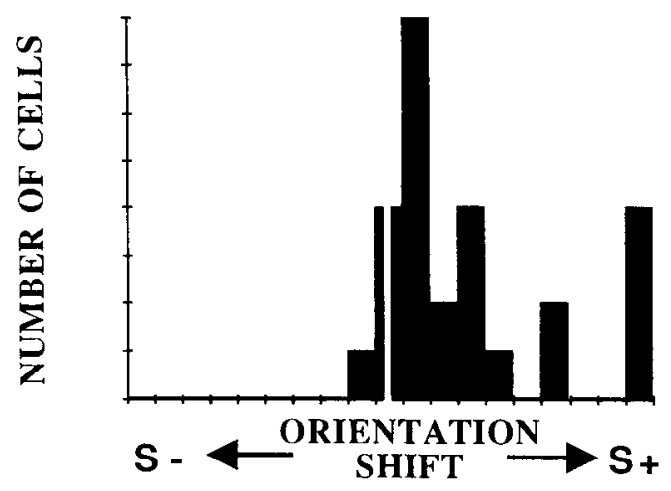

b

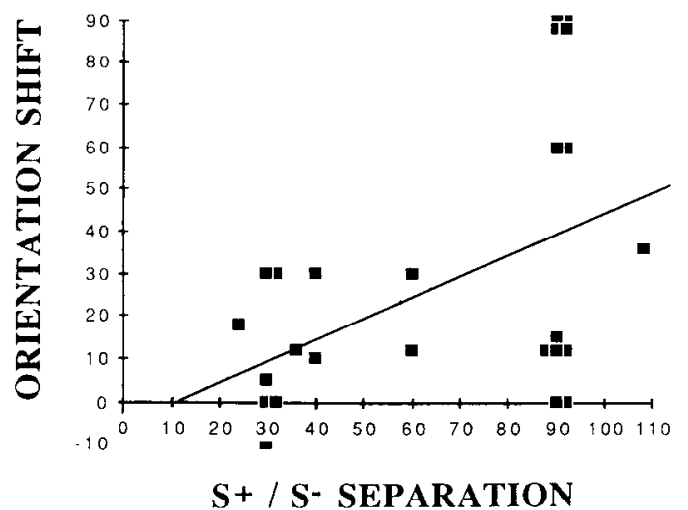

C

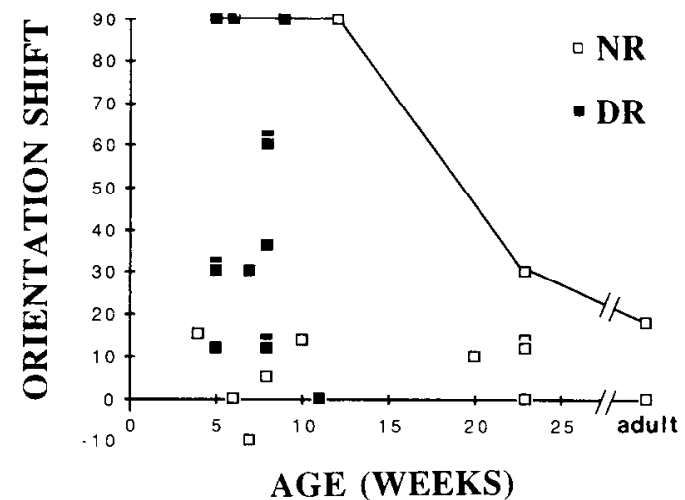

d

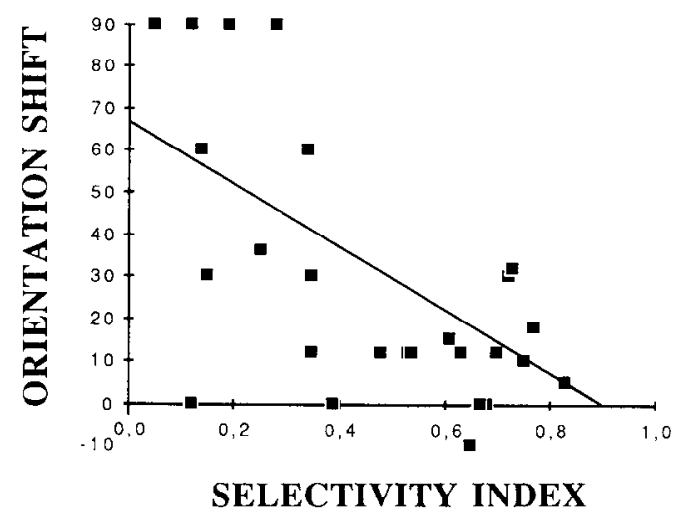

Figure 10. Reorganization of orientation tuning in "modified" cells: quantitative analysis of the shift of preferred orientations of 45 cells for which orientation tuning curves were recorded before and after pairing. Twenty-eight of these cells were "modified" after pairing (see Materials and Methods for criteria). $a$, Distribution of the amplitude in the shift of the preferred orientation given by the angular difference between the orientation abscissae of the peak responses observed after and before pairing. In all but one case this orientation shift was in favor of the reinforced orientation $\left(S^{+}\right)$. b, Relationship between the induced shift in orientation preference and the angular separation imposed between the $\mathbf{S}^{+}$and the $\mathrm{S}^{-}$orientations. A significant positive correlation was found between these two variables; the linear regression (continuous line; $r=+0.51 ; F$ test $p<0.0083$ ) predicts that orientation inputs are no longer separable when less than $12^{\circ}$ apart. The induced orientation shift corresponded to that imposed during the pairing procedure in only $23 \%$ of cases, and on average was less than the value expected if the reorganization had been complete (slope, 0.5 ), although it was of the same sign. $c$, The shift in the preferred orientation is plotted as a function of the age of the animal and of the rearing condition ( $N R$, normal rearing; $D R$, dark rearing). In spite of a lack of systematic relationship with age, the largest changes were observed during the critical period. The upper envelope (solid line) joining the points of maximal orientation shift can be interpreted as an estimation of the potentiality of the cell to be modified as a function of age. $d$, Relationship between the amplitude of the orientation shift and the initial orientation selectivity of the cell [given by the index Sel $\emptyset=1-$ (mean response/maximum response), in Frégnac and Bienenstock, 1981, and Bienenstock et al., 1982] determined from the orientation tuning curve established before the pairing procedure. A significant correlation $(r=-0.64 ; F$ test $p<0.0004)$ was found, indicating that the largest shifts of preferred orientation were obtained in cells that were initially nonselective.

end of the pseudopairing. In summary, although a significant control of suprathreshold postsynaptic activity during pairing is not a sufficient condition for the induction of changes, it appears to be a necessary step in gating plasticity.

The mean pairing time was $10-15 \mathrm{~min}$ and corresponded to at least 40 associations for each stimulus, $\mathbf{S}^{+}$and $\mathbf{S}^{-}$. However, these numbers probably do not represent the minimum number of associations required to induce a change: in some cases the current values necessary to enhance or depress the response to predetermined levels of firing progressively diminished during pairing, suggesting that the effect was already present before the end of this procedure. In three cells, we tried to reverse the changes induced by a first pairing procedure, by inverting the $\mathrm{S}^{+}$and the $\mathrm{S}^{-}$orientations used during the earlier associations. Only in one cell, recorded in a normally reared 6-week-old kitten, could the reorganization of the orientation tuning curve be completely reversed.

In half of the "modified" cells, changes in relative orientation preference and orientation selectivity were not accompanied by global excitability changes. In the remaining cases, long-lasting decreases and increases in baseline activity were found in similar proportions. Since comparable observations following pairing 
were made for "nonmodified" cells, excitability alterations induced by pairing appeared unrelated to the orientation specificity of the functional changes. Similar conclusions were reached independently in studies of binocular integration plasticity (Shulz. and Frégnac, 1992).

\section{Functional characteristics of the modified cells}

A qualitative study of the receptive field organization using stationary stimuli was performed on some cells submitted to pairing. In 22 cells, the overlap of ON and OFF subregions as well as the receptive field dimensions were mapped on the drawing table (see Materials and Methods). Sixteen cells were classified as simple and six as complex following Hubel and Wiesel's original classification (1962). The criteria used by Pettigrew et al. (1968) on quantitatively measured responses to moving slits corroborated the static classification. Fifty-six percent of the cells classified as simple and $83 \%$ of the complex cells showed a significant modification of their orientation selectivity. However, in view of this small sample, no obvious clear bias in receptive field properties emerged from the global population of "modified" cells, nor could laminar location be systematically related to the induction of functional changes.

On the other hand, parameters related to the degree of functional specialization of the cell assessed before pairing appeared more related to the cell's potential for plasticity. Although no clear dependence on age and rearing condition was found, the largest effects occurred in cells recorded between 5 and 12 weeks of age (see Fig. 10c). Changes in preferred orientation were significantly larger in cells with an initially weak orientation bias; such cells are most frequent in visually deprived kittens. When the "conditioned" cells from all animals are pooled, a negative correlation still exists between the orientation preference shift and the selectivity index computed from the tuning curve established before pairing (see Fig. 10d). These findings agree with previous suggestions that the kinetics of reorganization of orientation properties might critically depend on the initial functional state of cortical neurons (Frégnac, 1979a,b, 1985).

\section{Discussion}

A protocol of associative conditioning was developed that demonstrates that orientation selectivity can be modified during the time of recording of single cortical cells by a local control of coactivity. Following several tens of associations, about onethird of the "conditioned" cells ( 27 of 87 ) showed significant changes in relative preference between the two test orientations, which in all cases favored the stimulus paired with a high level of response during conditioning. Changes were found in both kitten and adult visual cortex, but the largest effects were observed in nonoriented cells, recorded in deprived kittens at the peak of the critical period. Adaptation of orientation preference generally did not involve the emergence of responses de novo, but from long-term modification of previously existing responses.

In addition, the generalization of the effects could be studied for orientations other than those used during conditioning. Modifications in the orientation tuning profile were observed in a significant number of cases ( 28 of 45 ) and consisted of a displacement of the peak of preferred responses-which was often incomplete, but in all but one cell corresponded to a shift toward the reinforced orientation - or the appearance of a significant polar asymmetry favoring the $\mathrm{S}^{+}$orientation region.
Such changes could also be induced in juvenile and adult cats, provided that the two stimuli used for pairing were in the cell's initial orientation spectrum. These modifications in tuning selectivity appeared to be linked to the competitive imbalance imposed between the two orientations $\mathrm{S}^{+}$and $\mathrm{S}^{-}$during the conditioning procedure: as a rule, a gain in responsiveness was observed for orientations centered around the "positively reinforced" stimulus and a loss of competence around the "negatively reinforced" one, independently of their angular separation. This pattern of orientation dependence contrasts with spontaneous changes of visual excitability, which affect uniformly the orientation tuning (Frégnac and Bienenstock, 1981). It also differs strikingly from changes reported during bicuculline iontophoresis, where in most cases a decrease in selectivity was found due to the blocking of a generalized "iso-orientation" inhibition process, but was not accompanied by a change in orientation preference (Albus and Baumfalk, 1989).

The "covariance" algorithm and the experimental data presented above suggest that these functional changes may be based on modifications in synaptic efficacy. In most cases, the observed changes agreed with the predictions of the covariance hypothesis, namely, the potentiation of the $\mathbf{S}^{+}$pathway and the depression of the strength of synapses subserving the $S^{-}$stimulus. The fact that no modification of receptive field properties was induced by visual stimulation alone or by randomized pairing procedures - for which no systematic overlap was imposed between the iontophoretic control and the presentation of the test stimuli-supports the existence of postsynaptic plasticity thresholds dependent on the membrane potential of the target neuron at the time of arrival of presynaptic impulses (see also Frégnac et al., 1990).

\section{Validation of the covariance hypothesis}

A tacit assumption in the present study is that changes in covariance levels are indeed achieved by a selective control of the firing state of the postsynaptic neuron. However, although postsynaptic activity changes were continuously monitored during pairing, the possibility that afferent activity, which remains an unknown variable in our experiment, was also affected by iontophoretic action cannot be entirely ruled out. Although the increases in extracellular $\mathrm{K}^{+}$concentration - produced both during positive current application through the $3 \mathrm{M} \mathrm{KCl}$ extracellular electrode and during periods of high postsynaptic activity-are damped when reaching a fixed ceiling level (around 10 $\mathrm{mM}$ ) and are buffered rapidly by the extracellular medium (Heinemann and Lux, 1977) and surrounding glia (Gardner-Medwin, 1983), there is evidence for a direct effect on synaptic transmission (Weight and Erulkar, 1976; Malenka et al., 1981; Yarom and Spira, 1982; reviewed in Nicholson, 1983; Sykova, 1983). Pulses of potassium could induce a phenomenon known as primary afferent depolarization (PAD), which causes a reduction in action potential amplitude due to the depolarization of the terminals, and indirectly leads to a reduction in transmitter release (Singer and Lux, 1973; ten Bruggencate et al., 1974). Although PAD could result in presynaptic inhibition, the increase of extracellular $\mathrm{K}^{+}$concentration may paradoxically counterbalance this effect by a direct increase in transmitter release from presynaptic sites (see, e.g., Blaustein, 1975; Sellstrom and Hamberger, 1977). In particular, Cooke and Quastel (1973; but see Somjen, 1979) proposed that $\mathrm{K}^{+}$accumulation during EPSP generation may increase the release of $\mathrm{ACh}$ at the rat neuromuscular junction. A similar mechanism could operate 
in visual cortex, since increases in catecholamine levels have been demonstrated during specific activation of thalamic afferents (Marrocco et al., 1987). However, in view of the mainly inhibitory action of noradrenaline (NA) iontophoresis on visual cortical activity (Videen et al., 1984), variations in the presynaptic release of NA seem unlikely to account for the strong depolarizing effect of our potassium pulses.

A second limitation for the separation of pre- and postsynaptic factors results from the fact that the pairing procedure not only affects the temporal correlation between presynaptic and postsynaptic impulses, but also modifies the actual number of action potentials emitted by the target cell in the intracortical network. Since iontophoresis was maintained throughout the presence of the stimulus across the receptive field, which in visual cortex could last up to a few seconds, recurrent activity arising from intracortical loops (Gilbert and Wiesel, 1979) or from reverberating circuits (Ferster and Lindström, 1985) could also be altered. These remarks stress the intrinsic difficulty in delineating the role of suprathreshold postsynaptic activity in synaptic plasticity, due to the existence of fast-acting feedback loops.

Despite these potential sources of contamination of the presynaptic message, our working assumption of a selective control of the postsynaptic membrane potential is supported by two findings. (1) During constant iontophoresis, the orientation preference remains invariant whatever the applied current level (less than $\pm 10 \mathrm{nA})$. For a given cell, all orientation tuning profiles obtained under these different conditions can be predicted from the curve established at the most positive current by subtracting a constant and by thresholding negative values to zero. In addition, since most recordings were made within the close proximity of the cell, as judged from the amplitude and shape of the spike (up to $40 \mathrm{mV}$, with a polarity similar to that of intracellular recordings and often showing an S-D inflexion), it is likely that the main iontophoretic effect was a direct control of postsynaptic membrane potential (depolarization or hyperpolarization). It seems indeed difficult to admit that local iontophoresis would affect the extracellular medium and the release mechanisms at all visually driven synapses in a uniform and coherent way independently of the distance between the tip of the electrode and the respective locations of synaptic inputs to the recorded neuron. (2) The functional modifications following differential pairing were clearly dependent on the sign of the imposed control of postsynaptic activity (potentiation for $\mathrm{S}^{+}$; depression for $\mathbf{S}^{-}$). The possibility of an artifactual alteration in synaptic transmission induced by the pairing procedure is ruled out by the finding that virtually all changes required temporal contiguity between pre- and postsynaptic activity, and occurred in a systematic and predictable direction: the change in relative responsiveness to the two test stimuli was in all but one case in favor of the one paired with an increased level of postsynaptic discharge.

In order to interpret further the functional changes in terms of alterations of synaptic efficacies, an additional assumption on input separability must be made. The differential pairing procedure used in our protocols requires that the two stimuli used during pairing activate distinct sets of synapses. By comparing the various cells for which orientation tuning could be established before and after pairing, a striking relationship emerges: the observed shift in orientation preference was significantly correlated with the orientation difference between $\mathrm{S}^{+}$ and $S^{-}$(with a slope of about +0.5 ). This relationship leads to the prediction that there is a threshold of angular separation between $\mathrm{S}^{+}$and $\mathrm{S}^{-}$below which no significant modification can occur. This threshold value (around $12^{\circ}$ ) is comparable to the proposed shift in orientation preference separating neighboring orientation columns (Hubel and Wiesel, 1962), and to the halfwidth at half-height of orientation tuning curves of cortical cells (Orban, 1984), which suggests that cortical columns encoding distinct orientations must first be activated, in order to increase the selectivity of each input channel, before competitive processes can occur at the level of individual cells.

These indirect arguments then suggest that a potential locus for synaptic changes could be the corticocortical synapses involved in horizontal intracortical connectivity (Ts'o et al., 1986; Bolz and Gilbert, 1989; Gilbert and Wiesel, 1989). In the adult, these connections preferentially link functional columns corresponding to similar orientations (but see Matsubara et al., 1987). The situation might be quite different in the developing cortex, since horizontal connectivity appears diffuse at eye opening, and its maturation is accompanied during the first 4-6 postnatal weeks in the cat by a progressive clustering into spatially separated domains (Luhmann et al., 1986; Callaway and Katz, 1990). The neuroanatomical reordering and/or stabilization of long-distance connections seems to depend to a certain extent on early visual experience, and could correspond to a clustering of the connectivity equivalent to a progressive restriction in the orientation difference between converging afferents or between pre- and postsynaptic partners (Tsumoto et al., 1987). The involvement of this developmental pattern in orientation plasticity is supported by our observation that the substrate available for orientation competition is more limited in juvenile and adult cats than in kittens at the peak of the critical period. However, input separability might be less easily achieved in younger kittens than in older animals because of the broader orientation tuning in immature neurons.

\section{Visual cortical plasticity and synaptic potentiation}

A classical NMDA-dependent scenario for synaptic potentiation (reviewed in Collingridge and Singer, 1990; Rauschecker, 1991) seems appropriate to explain the effects of our $\mathrm{S}^{+}$protocol where shifts toward stimulus characteristics paired with high extracellular potassium concentrations and postsynaptic depolarization. Several additional arguments suggest that the use of high potassium concentration pulses could efficiently promote NMDA-dependent processes: raised extracellular potassium concentration enhances synaptic activation of NMDA receptors (Poolos and Kocsis, 1990) and relieves the blockade by magnesium of NMDA-induced cGMP production (Carter et al., 1987).

The choice of external potassium as a local "positive reinforcer" was initially based on two reasons. The first is that it allowed the experimenter to mimic, at the recording site, changes of extracellular potassium concentration observed in cat visual cortex after simultaneous stimulation of specific and unspecific afferents (Lux and Singer, 1973). Repeated association of visual activation and mesencephalic reticular stimulation is indeed one of the rare protocols in the anesthetized and paralyzed preparation susceptible to induce receptive field modification (Singer and Rauschecker, 1982). It has also been shown in this case that transient decreases of extracellular calcium concentration are reliable indicators of the onset of visual cortical plasticity (Geiger and Singer, 1986). In this respect, it is interesting to note that iontophoresis with high potassium concentrations results 
in large increases in intracellular calcium (L. C. Katz, personal communication). $\Lambda$ recent report in hippocampus by Barrionuevo and collaborators (Fleck et al., 1990) further demonstrates that LTP-like phenomena can be induced by transient increases in extracellular potassium. The second reason is that varying potassium concentration may influence not only the postsynaptic firing of the recorded neuron but also the membrane potential of neighboring glia. It is known from the intraglial records of Kelly and Van Essen (1974) that the graded potential of glial cells shows the same orientation selectivity as the neurons in the same column. Thus, localized pairing of afferent activity with different levels of glial depolarization in the same cortical column could achieve a better clamp of the dendritic processes of the "conditioned" neuron. This idea has been directly tested in hippocampus, where pairing presynaptic activity with intracellularly imposed depolarization in a nonspiking cell induced synaptic potentiation in neighboring neurons (Sastry et al., 1988; see also Kossel et al., 1990).

The duration of the observed changes is not as easy to interpret as evidence for classical LTP processes. In most modified cells, effects were observed immediately after the end of the pairing procedure (as it was the case following ocular dominance protocols, in Shulz and Frégnac, 1992) and were retained for variable periods, lasting from $10 \mathrm{~min}$ to several hours (see Fig. 4). It is probable that postpairing potentiation could be an intermediate stage before installment of LTP, and the exact duration of the processes might be critically dependent on various factors such as the quality of control of activity achieved during pairing (which might differ from cell to cell depending on the position of the iontophoretic channel and on the cell's morphology), and the physiological state of the in vivo anesthetized and paralyzed preparation. Gating and permanence of the effects of delayed visual experience have been shown to depend on the integrity of cxtrarctinal signals such as extraocular proprioception (reviewed in Frégnac, 1987), and on subsequent anesthesia levels (Rauschecker and Hahn, 1987). Nevertheless, certain cells showed delayed effects sometimes preceded by transient depression of global activity. This kinetic is reminiscent of the time course of hippocampal and cortical LTP, which is generally preceded by posttetanic depression (Gustafsson et al., 1989; Artola et al., 1990; Zalutsky and Nicoll, 1990), and the lag observed occasionally in the expression of the functional change could result from the progressive development of second-messenger processes (Davies et al., 1989). Consequently, the terminology "long/short term" should not be understood here in the usual LTP sense, but has been used here to differentiate our findings from various forms of fatigue, adaptation, or habituation described previously in the adult cat (review in Frégnac and Imbert, 1984).

\section{Visual cortical plasticity and synaptic depression}

Much less experimental evidence is available concerning the effects of pairing afferent stimulation with hyperpolarization of the target cell, which would constitute the equivalent of the $\mathrm{S}^{-}$ condition in our protocol (Frégnac et al., 1988). Nevertheless, several comparative population studies demonstrate cortical plasticity in the absence of postsynaptic firing imposed by local injection of a $\mathrm{GABA}_{\mathrm{A}}$ agonist (Reiter and Stryker, 1988) or by inactivation by a high concentration of NMDA (Bear et al., 1990). These results are in fact fully predicted by our own working hypothesis, according to which a maintained period of failure in synaptic transmission should selectively weaken the efficacy of any active synapses. This situation is comparable to that imposed locally in our experiments, during an imposed negative level of covariance $\left(\mathrm{S}^{-}\right)$produced by the blockade or reduction of the response of the recorded cortical neuron (see Fig. 4 and Fig. 5a, lower row; Table 1).

Recent in vitro studies in visual cortex (Frégnac et al., 1990; Friedlander et al., in press) suggest that hyperpolarization paired with afferent stimulation may lead to synaptic depression of the active pathway. These results are supported indirectly by recent findings of Tsumoto and coworkers (Kimura et al., 1990) showing that variations in intracellular calcium concentration below or above baseline levels could be a key factor in deciding the sign of the synaptic change. Comparison of these in vitro data with the present in vivo findings suggests that changes in membrane potential from the resting level below or above certain threshold values may lead to adaptation of postsynaptic integration via antagonistic NMDA- and non-NMDA-dependent second-messenger processes; these changes would respectively result in decrease or increase of the efficacy of recently activated synapses. This scheme differs slightly from the explanation proposed by Artola et al. (1990), who also described in a recent report distinct voltage thresholds for long-lasting depression and potentiation. The plasticity thresholds found in their experimental situation are thought to be reached in succession, when depolarizing the postsynaptic neuron more and more strongly. Our in vivo data could still accommodate this scenario, by assuming that the $S^{-}$protocol does not prevent stimulus-triggered depolarizations but significantly reduces the normal activation of NMDA-dependent processes, leading to a situation where only the depression mechanism is expressed.

\section{Possible links between developmental and adult plasticity}

A major conclusion from our experimental test of the covariance hypothesis is that imposed temporal correlation between postsynaptic activity and given characteristics of the visual message induces functional modifications in receptive field properties analogous to those observed during epigenetic development (Blakemore and Cooper, 1970; Stryker et al., 1978): selective exposure to a "reinforced" orientation leads to a progressive capture of visual cortical responsiveness by the experienced stimulus (see also Rauschecker, 1982). About onc-third of cells submitted to our differential pairing procedure adapt their functional preference. For the remaining contingent of unmodified cells, two hypotheses can be made. First, we cannot exclude that a certain proportion of cells could be under the control of strong endogenous constraints and insensitive to our pairing protocols. One of us (Y.F.) made earlier a similar suggestion (hypothesis of "differential modifiability," Frégnac and Imbert, 1978) based on the study of the development of orientation selectivity. Related reports (Leventhal and Hirsch, 1977; Singer, 1981) also support the notion of input-resistant "seeds" in the orientation network. Second, the proportion of modified cells might depend on the quality of control of the postsynaptic state and on the presence or absence of gating factors. Data in favor of this interpretation can be found in the work of Baranyi and coworkers in the motor cortex of the adult cat (Baranyi and Féher, 1981; Baranyi and Szente, 1987). From the comparison of these two studies using a supervised learning scheme comparable to our $\mathrm{S}^{+}$protocol, the proportion of modifiable cells was found to be twice as high in awake cats as in anesthetized animals. Furthermore, the proportion of modifiable cells was higher when using single-electrode voltage clamp than current clamp during 
pairing. These observations are compatible with present knowledge on the role of postsynaptic membrane potential in the induction of synaptic potentiation (Kelso et al., 1986). Accordingly, one may reasonably assume that extracellular potassium iontophoresis is less effective in producing synaptic potentiation than single-electrode voltage clamp, and this might lead in fact to an underestimation of the proportion of modifiable cells in our study. It is then all the more remarkable that about a third of the cells were found to be modifiable.

The second, more unexpected, conclusion is that a similar proportion of visual cortical neurons - under artificial conditions of forced coactivity - are able to adapt their functional specificity in a similar way, even in the juvenile and adult cat. Our findings are also in agreement with an increasing number of in vitro reports that show that adult cortical cells under certain input/output conditions might still undergo a plastic change. An important issue in the interpretation of data is to decide whether these physiological effects seen in the adult as well as in young animals are related to visual epigenesis, or rather are a possible substrate for adaptation and aftereffects of visual responses that have been described both in children and adult humans. The phenomenology of the changes we found in the adult cat (see also Shulz and Frégnac, 1992) differ strikingly from that classically reported in the psychophysical literature of visual adaptation. In the latter case, modifications of visual responses, some of which have been shown to be clearly mediated cortically rather than precortically, usually require high rates of dynamic stimulation (above $1 \mathrm{~Hz}$, compared with the frequency of $0.1-0.2 \mathrm{~Hz}$ used in the present study), or long periods of continuous exposure (typically $1 \mathrm{~min}$ compared to a few seconds at most in the present study). Although some authors noted that the effects could be enhanced during the course of repetitive stimulation, the consecutive aftereffects are of much shorter duration (few tens of seconds at the most) than those described here. A recent extensive study of aftereffects induced by a conditioning exposure to adapting gratings quantitatively analyzes a certain number of features that can be compared with our study (for details, see Saul and Cynader, 1989, their Fig. 8). First, aftereffects generally corresponded to a reduced level of response for the adapting stimulus. In our study, potentiation was often observed for the $\mathbf{S}^{+}$feature. Second, aftereffects were largely independent of the direction of the adapting grating. Most changes we observed after pairing with unidirectional stimuli were orientation and direction selective (see Figs. $6 a, 7$, left). Third, aftereffects were detectable when adapting stimulation was maintained for $5 \mathrm{sec}$ or more, and they lasted for less than $5 \mathrm{sec}$. Presentation of our stimuli (bars and not gratings) was shorter than $5 \mathrm{sec}$ and was reiterated every 5-10 sec. Fourth, aftereffects were strongest at the adapting orientations matching the preferred orientation. This was not the case for our $\mathrm{S}^{+}$protocols as summarized in Figure 9 . In the case of selective exposure to a fixed-orientation stimulus for several days, longterm adaptation effects have been described that all correspond to a decreased sensitivity to the conditioned stimulus, a result that is opposite to that found following $\mathrm{S}^{+}$pairing (Creutzfeldt and Heggelund, 1975). Of course the major difference remains that our protocol includes, in a sense, its own control: two orientations are being presented the same number of times; the effect is differential and depends on the control of postsynaptic activity associated with each orientation. We conclude that the low rate of repetition of the individual stimuli used in our study as well as their duration do not constitute an adapting sequence of stimulation able per se (without iontophoretic action) to produce short- or long-term aftereffects.

It is in fact quite plausible that our artificial iontophoretic technique-adding an external "teacher" to a normally unsupervised system - uncovers a plasticity process that, under normal conditions, is not visible in the adult. We propose that visual cortical cells still retain a potential for plasticity even outside the critical period. This does not necessarily imply that it is expressed under normal conditions of sensory stimulation. Nevertheless, this epigenetic potential could be revealed under supcrvised learning conditions (as shown by the present studies), or following peripheral deafferentation, behavioral learning, and intracortical stimulation, as already demonstrated in the somatosensory cortex (reviewed in Merzenich et al., 1990; see also Gilbert and Wiesel, 1991). Rather than assuming irreversible regression of the adaptive capacities of neocortical neurons during postnatal life, the sensitivity profile of the critical period would be explained by a strong age dependence of the mechanisms regulating the expression of functional epigenesis.

\section{References}

Albus K, Baumfalk U (1989) Bicuculline induced changes in excitability and orientation selectivity of striate cortical neurones. Soc Neurosci Abstr 15:324.

Albus K, Wolf N (1984) Early postnatal development of neuronal function in the kitten's visual cortex: a laminar analysis. J Physiol (Lond) 349:153-185.

Artola A, Bröcher S, Singer W (1990) Different voltage-dependent thresholds for inducing long-term depression and long-term potentiation in slices of the rat visual cortex. Naturc 347:69-72.

Baranyi A, Féher O (1981) Long-term facilitation of excitatory synaptic transmission in single motor cortical neurones produced by repetitive pairing of synaptic potentials and action potentials following intracellular stimulation. Neurosci Lett 23:303-308.

Baranyi A, Szente MB (1987) Long-lasting potentiation of synaptic transmission requires postsynaptic modifications in the neocortex. Brain Res 423:378-384.

Bear M, Kleinschmidt A, Gu Q, Singer W (1990) Disruption of experience-dependent synaptic modifications in striate cortex by infusion of an NMDA receptor antagonist. J Neurosci 10:909-925.

Bienenstock E, Cooper LN, Munro P (1982) Theory for the development of neuron selectivity: orientation specificity and binocular interaction in visual cortex. J Neurosci 2:23-48.

Blakemore C, Cooper GF (1970) Development of the brain depends on the visual environment. Nature 228:419-478.

Blakemore C, Van Sluyters RC (1975) Innate and environmental factors in the development of kitten's visual cortex. J Physiol (Lond) 248:663-716.

Blaustein MP (1975) Effects of potassium veratridine and scorpion venom on calcium accumulation and transmitter release by nerve terminals in vitro. J Physiol (Lond) 247:617-655.

Bolz J, Gilbert CD (1989) The role of horizontal connections in generating long receptive fields in the cat visual cortex. Eur J Neurosci $1: 263-268$.

Callaway EM, Katz LC (1990) Emergence and refinement of clustered horizontal connections in cat striate cortex. J Neurosci 10:1134-1153.

Carew TJ, Hawkins RD, Abrams TW, Kandel ER (1984) A test of Hcbb's postulate at identified synapses which mediate classical conditioning in Aplysia. J Neurosci 4:1217-1224.

Carter CJ, Noel F, Scatton B (1987) Raised extracellular potassium relieves the blockade by magnesium of NMDA-induced cerebellar cyclic GMP production. Neurosci Lett 82:201-205.

Collingridge GL, Singer W (1990) Excitatory amino-acid receptors and synaptic plasticity. Trends Pharmacol Sci 11:290-296.

Cooke JD, Quastel DJM (1973) The specific effect of potassium on transmitter release by motor nerve terminal. J Physiol (Lond) 228: 435-458.

Creutzfeldt OD, Heggelund $P$ (1975) Neural plasticity in visual cortex of adult cats after exposure to visual patterns. Science 188:1025-1027.

Davies SN, Lester RAJ, Reyman KG, Collingridge GL (1989) Tem- 
porally distinct pre- and postsynaptic mechanisms maintain longterm potentiation. Nature 338:500-503.

Eccles J (1966) Cerebral synaptic mechanisms. In: Brain and conscious experience (Eccles J, ed), pp 24-58. Berlin: Springer.

Ferster D, Lindström S (1985) Augmenting responses evoked in area 17 of the cat by intracortical axon collaterals of cortico-geniculate cells. J Physiol (Lond) 367:217-232.

Fleck MW, Palmer AM, Barrionuevo G (1990) Characterization of an LTP-like phenomenon induced by a transient increase in extracellular potassium concentration. Soc Neurosci Abstr 16:491.

Frégnac Y (1979a) Development of orientation selectivity in the primary visual cortex of normally and dark reared kittens. I. Kinetics. Biol Cybern 34:187-193.

Frégnac Y (1979b) Development of orientation selectivity in the primary visual cortex of normally and dark reared kittens. II. Models. Biol Cybern 34:195-703.

Frégnac Y (1982) Développement de la sélectivité neuronale dans le cortex visuel primaire du chat. Doctorat d'Etat ès-Sciences Naturelles, Universitć Paris VI.

Frégnac $Y$ (1985) Functional multicompartment models: a kinetic study of the development of orientation selectivity. In: Models of the visual system (Rose D, Dobson VG, eds), pp 172-181. New York: Wiley.

Frégnac Y (1987) Cellular mechanisms of epigenesis in cat visual cortex. In: Imprinting and cortical plasticity (Rauschecker JP, Marler P, eds), pp 221-266. New York: Wiley.

Frégnac Y, Bienenstock E (1981) Specific functional modifications of individual cortical neurones, triggered by vision and passive eyemovement, in immobilized kittens. In: Pathophysiology of the visual system (Maffei L, ed), pp 101-108. Pisa: Junk

Frégnac Y, Imbert M (1978) Early development of visual cells in normal and dark reared kittens: relationship between orientation selectivity and ocular dominance. J Physiol (Lond) 278:27-44.

Frégnac Y, Imbert M (1984) Development of neuronal selectivity in the primary visual cortex of the cat. Physiol Rev 64:325-434.

Frégnac $Y$, Shulz D, Thorpe S, Bienenstock E (1988) A cellular analogue of visual cortical plasticity. Nature 333:367-370.

Frégnac Y, Smith D, Friedlander MJ (1990) Postsynaptic membrane potential regulates synaptic potentiation and depression in visual cortical neurons. Soc Neurosci Abstr 16:798.

Friedlander MJ, Frégnac Y, Burke $\mathbf{J}$ (in press) Temporal covariance of post-synaptic membrane potential and synaptic input. Role in synaptic efficacy in visual cortex. Prog Brain Res, in press.

Gardner-Medwin AR (1983) Analysis of potassium dynamics in mammalian brain tissue. J Physiol (Lond) 335:393-426.

Geiger H, Singer W (1986) A possible role of the calcium currents in developmental plasticity. Exp Brain Res Ser D 14:256-270.

Gilbert CD, Wiesel TN (1979) Morphology and intracortical projections of functionally characterized neurones in the cat visual cortex. Nature 280:120-125.

Gilbert CD, Wiesel TN (1989) Columnar specificity of intrinsic horizontal and corticocortical connections in cat visual cortex. J Neurosci 9:2432-2442.

Gilbert CD, Wiesel TN (1991) Dynamic properties of visual cortical cells. In: NATO advanced research workshop, Physiological and computational aspects of cortical functions, pp 28-29. Sirolo, Italy.

Gustafsson B, Asztely F, Hanse E, Wigström H (1989) Onset characteristics of long-term potentiation in the guinea-pig hippocampal CA1 region in vitro. Eur J Neurosci 1:362-394.

Hammond P, Andrews DP, James CR (1975) Invariance of orientational and directional tuning in visual cortical cells of the adult cat. Brain Res 96:56-59.

Hebb DO (1949) The organization of behavior. New York: Wiley.

Heinemann U, Lux H (1977) Ceiling of stimulus induced rises in extracellular potassium-concentration in the cerebral cortex of the cat. Brain Res 120:231-249.

Henry GH, Bishop PO, Tupper RM, Dreher B (1973) Orientation specificity and response variability of cells in the striate cortex. Vision Res 13:1771-1779.

Hirsch HVB, Spinelli DN (1970) Visual experience modifies distribution of horizontally and vertically oriented receptive fields in cats. Science 168:865-871.

Hubel DH, Wiesel TN (1962) Receptive fields, binocular interaction and functional architecture in the cat's visual cortex. J Physiol (Lond) 160:106-154.
Hubel DH, Wiesel TN (1963) Receptive fields of cells in striate cortex of very young, visually inexperienced kittens. J Neurophysiol 26:9941002.

Imbert M, Buisseret P (1975) Receptive field characteristics and plastic properties of visual cortical cells in kittens reared with or without visual experience. Exp Brain Res 22:25-36.

Kelly JP, Van Essen DC (1974) Cell structure and function in the visual cortex of the cal. J Physiol (Lond) 328:515-547.

Kelso SR, Ganong AH, Brown TH (1986) Hebbian synapses in hippocampus. Proc Natl Acad Sci USA 83:5326-5330.

Kimura F, Tsumoto T, Nishigori A, Yoshimura Y (1990) Long-term depression but not potentiation is induced in $\mathrm{Ca}^{2+}$-chelated visual cortex neurons. Neuroreport 1:65-68.

Kossel A, Bonhoeffer T, Bolz J (1990) Non-Hebbian synapses in rat visual cortex. Neuroreport 1:115-118.

I eventhal AG, Hirsch HVR (1977) Effects of early experience upon orientation sensitivity and binocularity of neurons in visual cortex of cats. Proc Natl Acad Sci USA 74:1272-1276.

Luhmann HJ, Martinez-Millan L, Singer W (1986) Development of horizontal intrinsic connections in cat striate cortex. Exp Brain Res 63:443-448.

Lux HD, Singer W (1973) Changes of extracellular potassium concentration in cat visual cortex after stimulation of specific and unspecific afferents. Pfluegers Arch S343:137R.

Malenka RC, Kocsis JD, Ransom BR, Waxman SB (1981) Modulation of parallel fiber excitability by postsynaptically-mediated changes in extracellular potassium. Science 214:339-341.

Marrocco RT, Lane RF, McClurkin JW, Blaha CD, Alkire MF (1987) Release of cortical catecholamines by visual stimulation requires activity in thalamocortical afferents of monkey and cat. J Neurosci 7 2756-2767.

Matsubara J, Cynader M, Swindale NW, Stryker MP (1987) Intrinsic projections within visual cortex: evidence for orientation-specific local connections. Proc Natl Acad Sci USA 82:935-939.

Merzenich MM, Recanzon GH, Jenkins WM, Nudo RJ (1990) How the brain functionally rewires itself. In: Natural and artificial parallel computation (Arbib M, Robinson A, eds), pp 177-210. Cambridge, MA: MIT Press.

Nicholson C (1983) Regulation of the ion microenvironment and neuronal excitability. New York: Liss.

Orban GA (1984) Neuronal operations in the visual cortcx. Studies of brain function. Berlin: Springer.

Pettigrew JD, Nikara T, Bishop PO (1968) Responses to moving slits by single units in cat striate cortex. Exp Brain Res 6:373-390.

Pettigrew JD, Cooper ML, Blasdel GG (1979) Improved use of tapetal reflection for eye-position monitoring. Invest Ophthalmol Vis Sci 18 : $490-495$.

Poolos NP, Kocsis JD (1990) Elevated extracellular potassium concentration enhances synaptic activation of $N$-methyl-D-aspartate receptors in hippocampus. Brain Res 508:7-12.

Purves RD (1981) Microelectrode methods for intracellular recording and iontophoresis. London: Academic.

Rauschecker JP (1982) Instructive changes in the kitten's visual cortex and their limitation. Exp Brain Res 48:301-305.

Rauschecker JP (1991) Mechanisms of visual plasticity: Hebb synapses, NMDA receptors, and beyond. Physiol Rev 71:587-615.

Rauschecker JP, Hahn S (1987) Ketamine-xylazine anesthesia blocks consolidation of ocular dominance changes in kitten visual cortex. Nature 326:183-185.

Rauschecker JP, Singer W (1981) The effects of early visual experience on the cat's visual cortex and their possible explanation by $\mathrm{Hebb}$ synapses. J Physiol (Lond) 310:215-239.

Reiter HO, Stryker MP (1988) Neural plasticity without postsynaptic action potentials: less-active inputs become dominant when visual cortical cells are pharmacologically inhibited. Proc Natl Acad Sci USA 85:3623-3627.

Sastry BR, Goh JW, May PBY, Chirwa SS (1988) The involvement of nonspiking cells in long-term potentiation of synaptic transmission in the hippocampus. Can J Physiol Pharmacol 66:841-844.

Saul AB, Cynader MS (1989) Adaptation in single units in visual cortex: the tuning of aftereffects in the spatial domain. Vis Neurosci 2:593-607.

Sejnowski TJ (1977a) Storing covariance with non-linearly interacting neurons. J Math Biol 4:303-321. 
Sejnowski TJ (1977b) Statistical constraints on synaptic plasticity. J Theor Biol 69:387-389.

Sellstrom A, Hamberger A (1977) Potassium stimulated gamma-amino-butyric acid release from neurons and glia. Brain Res 119:189198.

Shulz D, Frégnac Y (1992) Cellular analogs of visual cortical epigenesis. II. Plasticity of binocular integration. J Neurosci 12:1301-1318.

Singer W (1981) Topographic organization of orientation columns in the cat visual cortex (research report). Exp Brain Res 44:431-436.

Singer W, Lux HD (1973) Presynaptic depolarization and extracellular potassium in the cat lateral geniculate nucleus. Brain Res 64:17-33.

Singer W, Rauschecker JP (1982) Central core control of developmental plasticity in the kitten visual cortex. II. Electrical activation of mesencephalic and diencephalic projections. Exp Brain Res 47: 223-233.

Somjen GG (1979) Extraccllular potassium in the mammalian central nervous system. Annu Rev Physiol 41:159-177.

Stryker MP, Sherk H, Leventhal AG, Hirsch HVB (1978) Physiological consequences for the cat's visual cortex of effectively restricting early visual experience with oriented contours. J Neurophysiol 41: 896-909.

Sykova E (1983) Extracellular $\mathrm{K}^{+}$accumulation in the central nervous system. Prog Biophys Mol Biol 42:135-189.

ten Bruggencate G, Lux HD, Liebl L (1974) Possible relationships between extracellular potassium activity and presynaptic inhibition in the spinal cord of the cat. Pfluegers Arch 349:301-317.

Ts'o DY, Gilbert CD, Wiesel TN (1986) Relationships between horizontal interactions and functional architecture in cat striate cortex as revealed by cross-correlation analysis. J Neurosci 6:1160-1170.

Tsumoto T, Hata Y, Sato H, Hagihara K (1987) Functional development of neuronal connections in the kitten visual cortex studied by cross-correlation analysis. Neuroscience 22:\$237.

Tusa RJ, Palmer LA, Rosenquist AC (1978) The retinotopic organization of area 17 (striate cortex) in the cat. J Comp Neurol 177:213236.

Videen TO, Daw NW, Rader RK (1984) The effect of norepinephrine on visual cortex neurons in kittens and adult cats. J Neurosci 4:16071617.

Weight FF, Erulkar SD (1976) Modulation of synaptic transmitter release by repetitive postsynaptic action potentials. Scicncc 193:10231025.

Willshaw D, Dayan P (1990) Optimal plasticity from matrix memories: what goes up must come down. Neural Comp 2:85-93.

Yarom Y, Spira ME (1982) Extracellular potassium ions mediate specific neuronal interaction. Science 216:80-82.

Zalutsky RA, Nicoll RA (1990) Comparison of two forms of longterm potentiation in single hippocampal neurons. Science 248:16191624. 